\title{
La venda de les pintures medievals de la Torre del Tesoro de San Pedro de Arlanza: un negoci?
}

\author{
Immaculada Socias Batet \\ Universitat de Barcelona \\ isocias@ub.edu
}

Recepció: 26/06/2019, Acceptació: 21/09/2020, Publicació: 28/12/2020

RESUM

\begin{abstract}
La present recerca es basa en l'exhumació i la interpretació de fonts inèdites procedents sobretot de l'arxiu del Metropolitan Museum of Art, de Nova York. Són documents que detallen minuciosament el procés de venda dels magnífics frescs medievals de la Torre del Tesoro del monestir de San Pedro de Arlanza (Burgos) al Metropolitan Museum of Art per part de Josep Colominas i Roca i Josep Gudiol i Ricart, a la vegada que també evidencia els mecanismes del comerç de l'art, fenomen que constitueix una de les columnes vertebrals de la història del col-leccionisme i que il/lumina les dramàtiques vicissituds d'aquests frescs medievals als dos costats de l'Atlàntic.
\end{abstract}

Paraules clau:

comerç de l'art; venda de frescs medievals; Metropolitan Museum of Art; Josep Gudiol i Ricart; Josep Colominas i Roca; San Pedro de Arlanza

\section{AbStRact}

The sale of the mural paintings of the Treasure Tower of the San Pedro de Arlanza Monastery: A business deal?

This investigation uncovers and interprets unpublished sources from the archives of the Metropolitan Museum of Art of New York. These are documents that minutely detail the process to sell the magnificent medieval frescoes from the Treasure Tower of the Monastery of San Pedro de Arlanza, Burgos, to the Metropolitan Museum by Josep Colominas i Roca and Josep Gudiol i Ricart, who gained a fabulous profit from the sale. The investigation seeks to contribute, among other things, to understanding the mechanisms of the commercial art market; a phenomenon that constitutes a necessary and provocative backbone of the history of collecting, and sheds light on the dramatic vicissitudes of these frescoes, which were dismembered and separated on both sides of the Atlantic.

\section{Keywords:}

commercial art market; sale medieval frescoes; Metropolitan Museum of Art; Josep Gudiol i Ricart; Josep Colominas i Roca 
A bans de començar volem advertir que el nostre objectiu està centrat en el món del col-leccionisme i del comerç de l'art. En conseqüència, en aquesta recerca focalitzarem particularment l'atenció a l'entorn del desmembrament i la complexa venda dels frescs d'Arlanza a museus americans, finalitzant amb l'arribada de les restes del naufragi a Barcelona. Així mateix, atorgarem una rellevància especial a les actuacions de Josep Colominas i Roca i Josep Gudiol i Ricart, com a agents d'art i exponents d'una pràctica o d'una determinada ètica professional que ajuda a entendre el procés de compravenda de manera global. En definitiva, també tindrem en compte els paràmetres de la llei de l'oferta i la demanda artística de l'època. Com és conegut, l'extraordinària oferta de béns artístics existents a la Península al llarg del segle XIX i part del XX va ser generada per una situació de pobresa econòmica i cultural, mentre que la demanda estava impulsada pel desig de posseir béns que presentaven una aura resplendent $\mathrm{i}$ desitjable per als agents $\mathrm{i}$ les col-leccions d'art. Aquests aspectes representen les coordenades generals en què es desenvolupa la nostra recerca.

\section{Unes breus paraules sobre el monestir de San Pedro de Arlanza}

El monestir benedictí de San Pedro de Arlanza, situat a la localitat d'Hortigüela, prop de Burgos, va constituir, com es prou conegut, un dels centres medievals més rellevants de Castella ${ }^{1}$. La seva activitat es perllongà fins a la desamortització ${ }^{2}$ de Mendizábal, l'any i 835 , circumstància que en va implicar la dissolució com a institució religiosa, la venda de la majoria dels seus edificis i, en definitiva, l'abandó i la ruïna del cenobi.

A més, i com a conseqüència d'aquest fenomen, el monestir va patir un espoli continuat dels seus tresors. Alguns dels més significatius foren la portada de l'església, avui al Museo Arqueológico Nacional de Madrid; el probable sepulcre dels comtes de Castella, Fernán González i Sança, a la Col-legiata de Covarrubias, o la venda dels extraordinaris frescs murals de la Torre del Tesoro.

\section{La Torre del Tesoro}

La denominada Torre del Tesoro estava situada sobre el recinte capitular del monestir, i les dues estances es comunicaven mitjançant una escalinata. Amb el transcurs del temps, el paviment de la sala de la Torre del Tesoro es va enfonsar, fet que va motivar que alguns autors mal interpretessin que les pintures decoraven la sala capitular del monestir. La Torre del Tesoro estava ornamentada amb uns esplèndids frescs zoomòrfics d'autor controvertit, probablement de començaments del segle XIII, i constituïa un dels llocs més especials i recòndits del cenobi. A propòsit d'aquestes pintures, l'acadèmic i historiador de l'art Elías Tormo ${ }^{3}$ pensava que eren d'inspiració de la dinastia persa sassànida i que constituïen una baula d'extraordinari interès per conèixer la pintura hispana.

El cicle pictòric de la Torre del Tesoro estava format per una sèrie d'animals monumentals $i$ fabulosos, com ara el lleó (figura I4), el drac alat o serpent (figura I 5 ), un estrany ocell, un griu (figura I7) i unes sirenes ocells (figura i 8). Figures que tenien un fort caràcter simbòlic i que exercien a la vegada una funció de salvaguarda i custòdia del lloc. A sota d'aquests éssers ex- 
traordinaris corria un fris poblat per estrafolàries criatures. $\mathrm{Al}$ segle XVII es va produir un canvi radical en aquest espai, que va consistir en l'obertura de tres grans arcs, una actuació que va significar la destrucció dels frescs que ornaven aquest flanc. Però això no va ser tot. Com va succeir també en altres llocs, i a causa de la introducció dels nous estils artístics, sembla que també es va decidir redecorar aquest espai. Aleshores es van tapar les pintures medievals, considerades obsoletes, amb una capa de guix, i a fi que s'adherís perfectament a la paret es van fer diverses incisions sobre la superfície pictòrica de les imatges, com es pot observar, per exemple, en el cas del lleó (figura I).

Després va caure un dens núvol de silenci i oblit sobre aquests tresors medievals, fins que, a finals del segle XIX i principis del segle XX, va renéixer un interès per aquests frescs, promogut, entre altres, per Vicente Lampérez ${ }^{4}$ l'any I 909 i per Julien Chappée 5 i Luciano Huidobro l'any I9I 2, els quals van divulgar a escala internacional la problemàtica situació en què es trobaven les pintures de la Torre del Tesoro de San Pedro de Arlanza. En aquest sentit, Chappée comentava:

[...] La nef est un tas de décombres. La salle capitulaire est sans toit et les enduits de plâtre dont on avait recouvert l'intérieur au $\mathrm{XVII}^{\mathrm{e}}$ siècle tombent peu à peu. Sous ces enduits étaient des peintures murales du plus grand style et d'une conservation parfaite. La plus visible actuellement et la plus récemment rendue au jour est un grand lion, attribut de l'évangéliste e saint Marc. On aperçoit également un peu le boeuf de saint Luc. Il serait bien désirable que ces peintures soient relevées avant leur disparition prochaine [...] Les peintures ont été photographiées et ce n'est, il faut l'espérer, qu'un début.

Tanmateix, i malgrat les notícies sobre el delicat estat de conservació dels quimèrics frescs de San Pedro de Arlanza, encara passarien alguns anys abans que aquests no ocupessin un primer pla d'atenció i fossin protagonistes d'una història ben diferent.

\section{Algunes propostes sobre la salvaguarda dels frescs}

Com han referenciat alguns autors, durant el primer quart del segle $\mathrm{xx}$, diverses institucions $^{6}$, entre les quals hi havia la Dirección General de Bellas Artes, la Real Academia de Bellas Artes de San Fernando, la Real Academia de la Historia de Madrid, el Gobierno Civil de

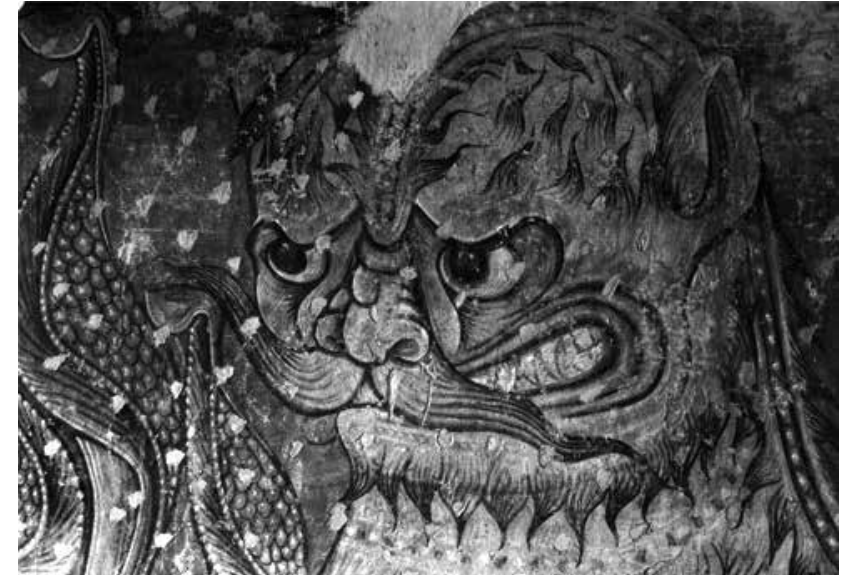

Figura 1.

Lleó de San Pedro de Arlanza, detall. Arxiu d'Arqueologia Catalana. Frick Art Reference Library.

Burgos i la Comisión Provincial de Monumentos Históricos y Artísticos, van reaccionar a causa de les queixes existents sobre la lamentable situació en què es trobaven els frescs de la Torre del Tresor. Inclús es va intentar que un pintor de Madrid fes una còpia dels murals que hi havia, la qual cosa no es va aconseguir per l'oposició dels que pensaven que eren els hereus legítims de les pintures, la família Valcárcel Barbadillo7. Sembla que aquests l'any i 924 van intentar arrencar els frescs de la Torre del Tesoro amb l'ajuda d'uns tècnics anglesos, actuació que va ser denunciada al governador civil de Burgos $^{8}$, que va paralitzar l'acció, perquè una de les qüestions clau que es discutien era esbrinar si els frescs es trobaven a l'àrea de titularitat pública o privada del monestir. Precisament a aquesta qüestió feia referència $\mathrm{Ma}$ nuel Gómez-Moreno y Martínez', membre de la Real Academia de la Historia:

Las pinturas en cuestión se hallan en un amplio recinto destechado y, según dicen, ruinoso, por detrás de los ábsides de la iglesia monasterial, y como esta parece ser propiedad del Estado, quizá quepa investigar si puede considerarse como anejo suyo el local de referencia, en cuyo caso resultaría su propiedad discutible [...] Su conservación es de honor histórico nacional y debe procurarse asegurarla por los medios adecuados. Se habla de peligros de una desaparición inminente por efecto de la intemperie; quizás haya interés en exagerar esta inminencia, pero queda descontada la necesidad de arrancar las pinturas de su sitio, operación delicada y costosa, estando a tal altura y siendo tan grande la superficie que ocupan; además, como los riesgos de un fracaso en dicha operación no pueden disimularse, la prudencia 


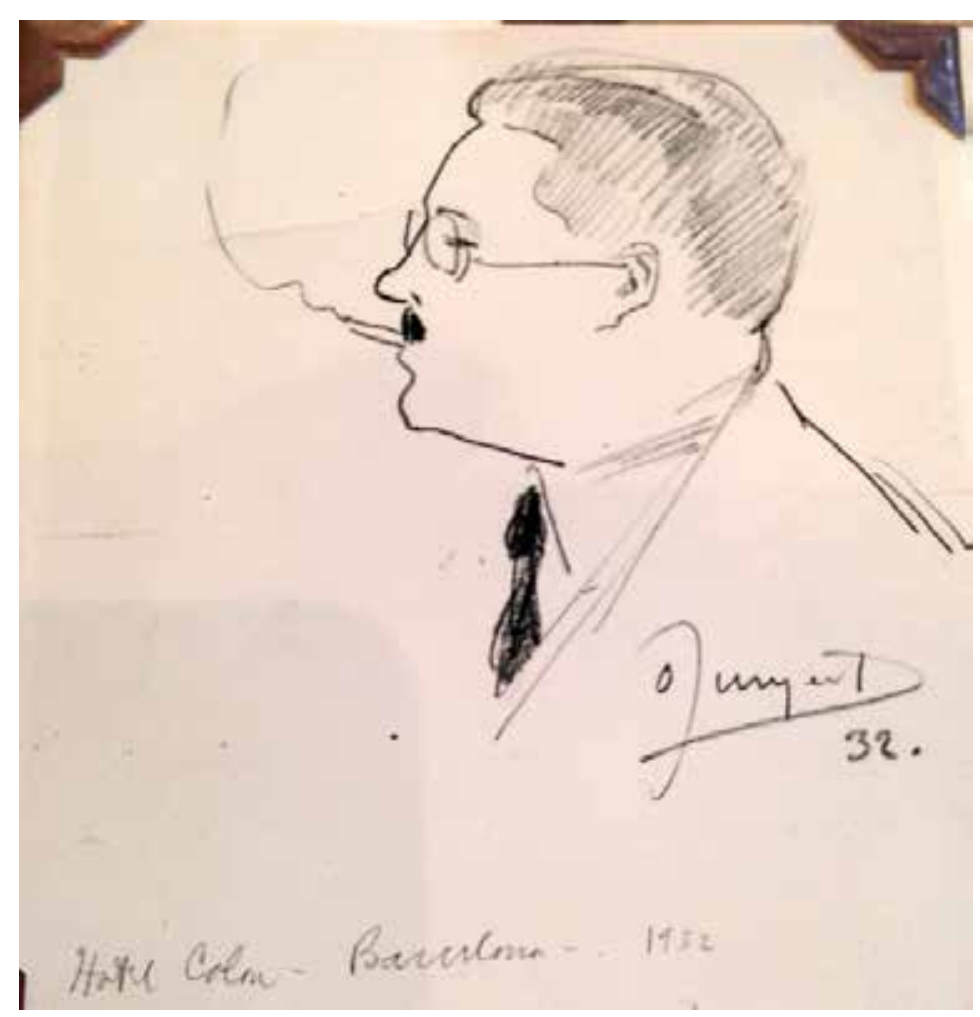

Figura 2.

Walter William Spencer Cook. Institute of Fine Arts. New York University.

aconseja obtener previamente fotografías y copias en color $[\ldots]$.

Mentre es discutia aquesta problemàtica, Alejandro Rodríguez de Valcárcel Barbadillo, fill de Carlota Barbadillo Fernández Loigorri, va oferir a l'Estat la compra dels murals per 10.000 pessetes. Elías Tormo ${ }^{10}$, assabentat d'aquesta qüestió, va considerar que l'oferta no era excessiva i recomanà remoure com més aviat millor les pintures a causa del seu delicat estat, opinió que també era compartida per Narciso Sentenach ${ }^{11}$, igualment acadèmic. I l'ocasió arribaria aviat.

\section{L'expedició arqueològica de 1927 de Walter William Spencer Cook i la remoció definitiva dels murals d'Arlanza}

Des de l'any 1926 es van dur a terme diverses expedicions, denominades arqueològiques en un sentit ampli, a Catalunya, Aragó, Navarra i Castella, impulsades pel College Art Association $(\mathrm{CAA})^{12}$ i dirigides pel medievalista Walter William Spencer Cook ${ }^{13}$ (figura 2). Freqüentment, aquestes expedicions seguien les pistes proporcionades per antiquaris ${ }^{14}$ que es dedica- ven a comprar tresors a esglésies, monestirs $\mathrm{i}$ convents, l'activitat dels quals va alertar la Comisión Provincial de Monumentos Históricos i Artísticos de Burgos, que els va denunciar diverses vegades.

El mateix Walter W. S. Cook ${ }^{15}$ va explicar que en una d'aquestes expedicions - segurament la de 1927 - va poder contemplar els frescs de la Torre del Tesoro en un estat molt crític i lamentable, per aquest motiu va considerar que si no s'hi actuava aviat i no s'arrencaven immediatament, podrien desaparèixer. La remoció devia ser immediata, perquè el $1929 \operatorname{Cook}^{16}$ anunciava que les pintures murals ja havien estat arrencades i que probablement serien destinades a un museu espanyol. A la tardor d'aquell mateix any el coneixement d'aquesta acció va tenir un polèmic $\mathrm{i}$ agre reflex a la premsa ${ }^{17}$. Eduardo de Ontañón ${ }^{18}$ referia a El Sol ${ }^{19}$ que uns individus havien comprat els murals d'Arlanza per I0.000 pessetes. Aquest autor deia que es trobaven a Vic, però no al Museu Episcopal d'aquesta ciutat, tot afegint que els nous propietaris s'havien compromès a no vendre'ls fora del país.

Altres personatges que també es van sumar a la denúncia ${ }^{20}$ van ser l'acadèmic Marceliano Santa María $a^{21}$, que n'havia defensat la compra per part de l'Estat, a la vegada que també criticava la diòcesi de Burgos per haver-ne permès la venda; Francisco Javier Sánchez Cantón ${ }^{22}$, futur director del Museu del Prado, que es queixava que els frescs no haguessin estat adquirits pel Museu de Vic, i l'arquitecte Teodoro Anasagas$\mathrm{ti}^{23}$, que lamentava que les famoses pintures, en comptes d'estar al Museu del Prado, estiguessin en mans d'un tal Buriel (potser es tracta d'una mala transcripció de Gudiol) i de l'arqueòleg Josep Colominas. Però, arribats en aquest punt, cal preguntar-se qui les va arrencar, qui les va vendre $i$ on van anar a parar. Seguidament intentarem contestar aquests interrogants.

\section{El comerç de l'art, un gran negoci}

Des de principis del segle XX, per no dir abans, el comerç de peces medievals havia proporcionat molts beneficis als seus promotors, uns guanys que probablement eren ben coneguts per l'arqueòleg Josep Colominas i Roca ${ }^{24}$ i l'arquitecte Josep Gudiol i Ricart ${ }^{25}$ (figura 3), els quals van aconseguir fer un suculent negoci amb la venda dels frescs de San Pedro de Arlanza.

Cal considerar que entre Colominas i Gudiol hi havia una estreta relació, fet que els va impulsar a publicar alguns treballs conjuntament ${ }^{26}$ (figura 4) i també a promoure negocis relatius al comerç de l'art. Sembla ser que al voltant de $1927^{27}$ tots dos tenien una botiga dedicada al 

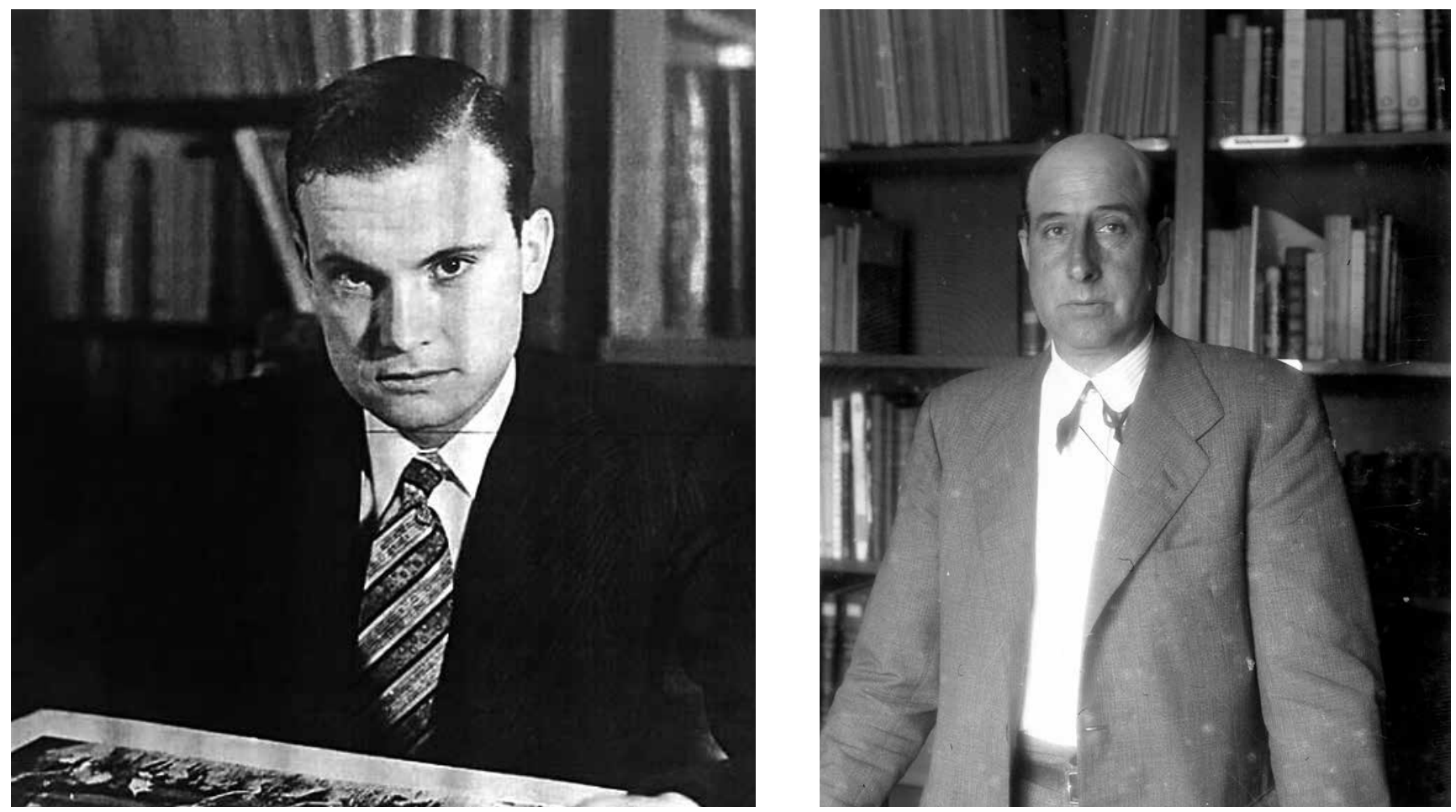

Figura 3.

Esquerra: Josep Gudiol i Ricart. Arxiu de l’Institut Amatller d'Art Hispànic; dreta: Josep Colominas i Roca. Museu Arqueològic de Catalunya, arxiu fotogràfic.

món de les antiguitats que s'anomenava $\mathrm{La} \mathrm{Sa-}$ cristía $^{28}$ i que estava situada al carrer de la Cor-

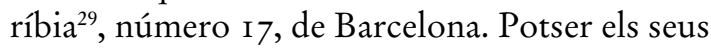
socis capitalistes ${ }^{30}$ en aquest negoci van ser dos potents col-leccionistes catalans, Ròmul Bosch i Catarineu ${ }^{31}$ i Teresa Amatller ${ }^{32}$ i Cros, la qual tindria un rellevant paper en la trajectòria vital de Josep Gudiol i Ricart.

També per aquesta època Josep Gudiol i Ricart va crear un taller de fotografia i restauració de pintures, l'Arxiu d'Arqueologia Catalana ${ }^{33}$, el qual va tenir la seva primera seu a Vic i després fou traslladat a Barcelona.

\section{L'actuació de Josep Gudiol i Ricart a la Torre del Tesoro}

Com apuntàvem anteriorment, probablement Colominas i Gudiol van conèixer la dramàtica situació dels murals d'Arlanza a través de Walter W. S. Cook, atès que aquest medievalista americà mantenia relacions amb el Museu Episcopal de Vic i amb el seu director, l'arqueòleg Josep Gudiol i Conill ${ }^{34}$ (I872-I93I), oncle de Gudiol i Ricart. Sigui com sigui, l'any I 928 Josep Gudiol ja estava treballant a San Pedro de Arlanza ${ }^{35}$. Ell, que llavors era un jove arquitecte de 24 anys, va realitzar el traçat d'alguns dels plànols del monestir (figures 6 i 7 ) i els diagrames $^{36}$ de les figures murals (figures 8, 9 i ro),

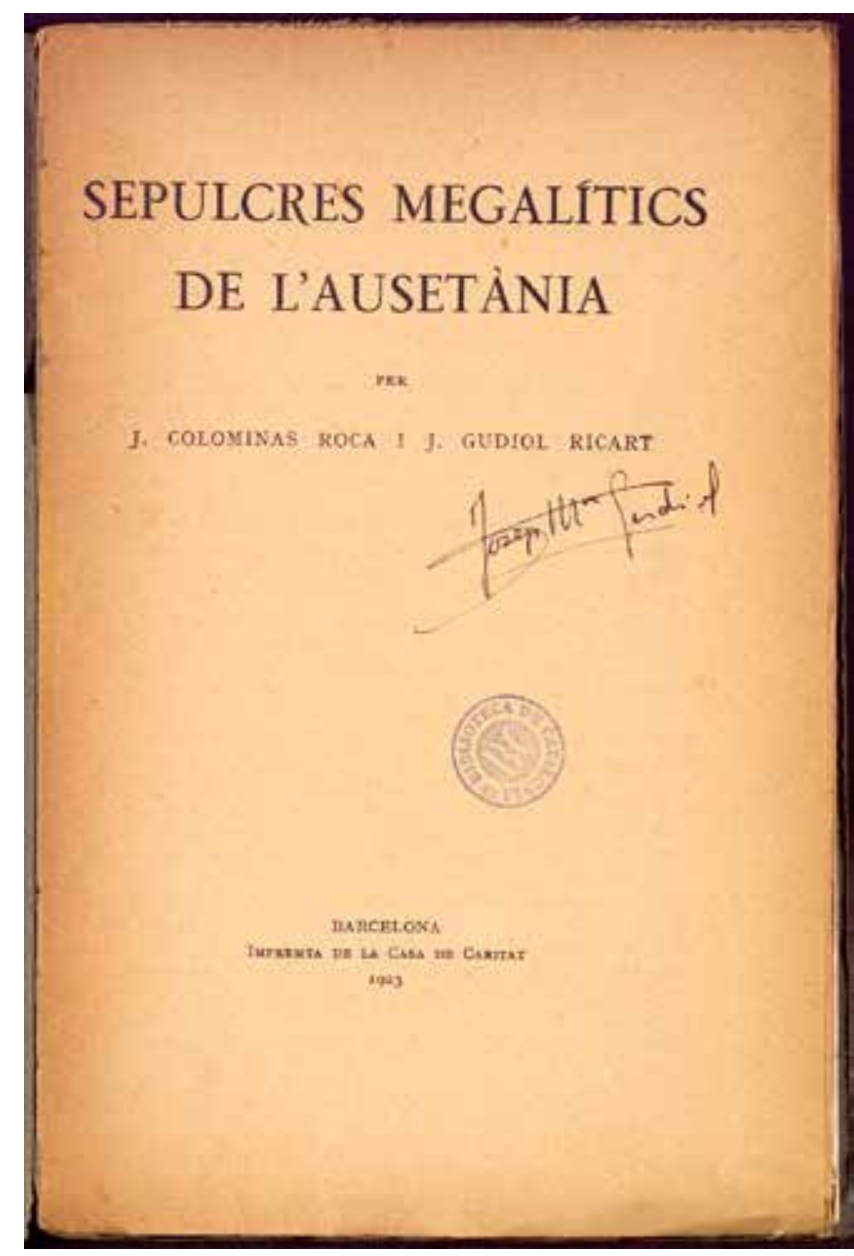

Figura 4.

Josep Colominas i Roca i Josep Gudiol i Ricart (1923), «Sepulcres megalítics de l'Ausetània». Quaderns d'Estudi, 15, p. 331-383. Biblioteca de Catalunya. 


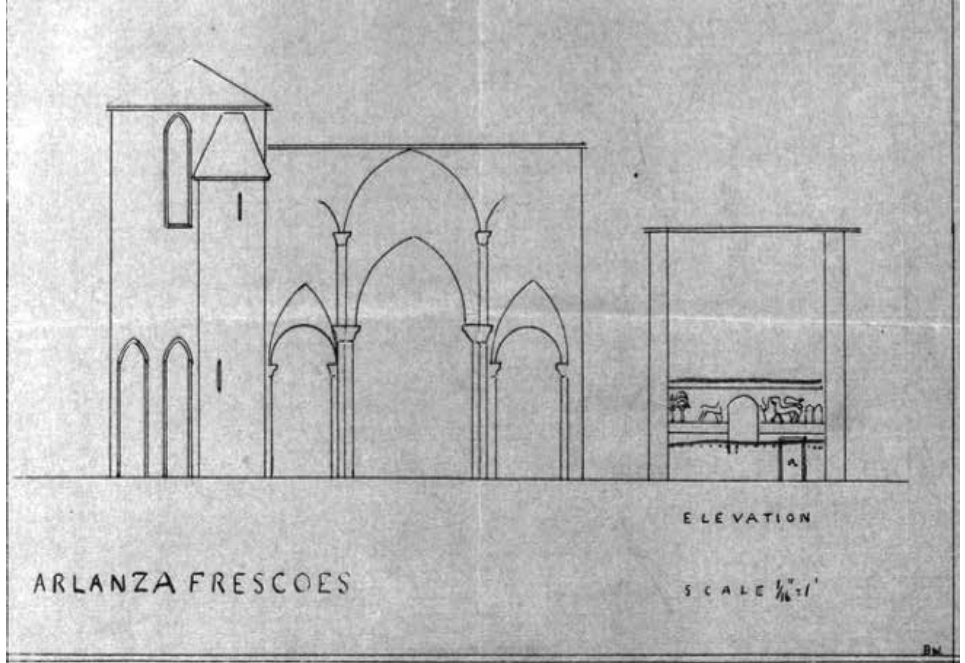

Figura 5.

Josep Gudiol i Ricart. Alçat del monestir de San Pedro de Arlanza. Frick Art Reference Library.

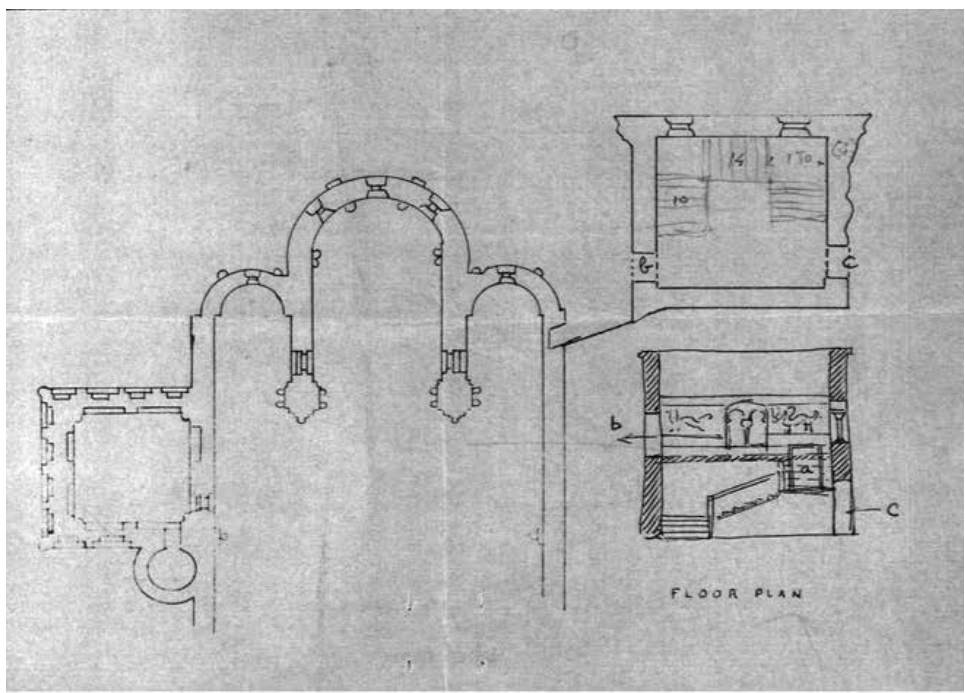

Figura 6.

Josep Gudiol i Ricart. Planta de l'absis del monestir de San Pedro de Arlanza i Torre del Tesoro. Frick Art Reference Library.

a més, va alliberar els frescs de la capa de guix que els cobria per transferir-los posteriorment al llenç. Però Josep Gudiol també va realitzar una magnífica i coneguda sèrie fotogràfica sobre el procés de remoció de les pintures. Aquestes imatges, juntament amb les captades per altres fotògrafs ${ }^{37}$, constitueixen un material molt valuós, perquè permeten tenir una idea global del treball realitzat: els frescs en el seu emplaçament original, la capa de guix que els cobria, així com la remoció, la restauració i la transferència posterior.

D'altra banda, cal subratllar que un dels actors clau en aquest procés va ser James Joseph Rorimer $^{38}$, conservador $\mathrm{i}$ després director del Metropolitan Museum of Art (figura Io), que era un any més jove que Josep Gudiol.
Precisament Rorimer ${ }^{39}$ confirmava que el I928, un any després de l'expedició de Walter Cook, Josep Gudiol ja treballava en la remoció de les pintures d'Arlanza i explicava que Gudi$\mathrm{ol}^{40}$ havia escrit un document sobre les pintures de la Torre del Tesoro, text que considerava molt interessant per comprendre el lloc:

The frescoes covered the walls of the second floor of a building like a large tower. I remember that I gave you some drawings that show the exact composition of the whole. The entrance to this painted room was through the very small portal B, which probably communicated this room with the sacristy of the church; and by a great staircase that started from the ground floor with a portal $\mathrm{C}$ that was open to a small cloister of the convent. The interior of this painted stone tower was remodelled in the seventeenth or eighteenth century and it was very difficult to reconstruct the exact original form. I'm sure the portawas modern. I regret now being of little help [...]. When I was in Arlanza, I was quite stupid for not making a careful elevation of this important building [...]. (Figures 6 i 7 )

\section{El fulgor de l'art medieval als Estats Units}

Deixant momentàniament les complexes vicissituds dels murals d'Arlanza, cal recordar breument l'important paper exercit per l'art hispànic a les diverses exposicions, com la de Chicago el I 893, o la seva presència en moltes col-leccions americanes. Però, a més d'aquests esdeveniments, cal també tenir present el rol desenvolupat per algunes de les principals universitats dels Estats Units a l'entorn de l'art medieval, escenari, en certa manera, complementari a la problemàtica que estem tractant. A principis del segle XX algunes universitats, com ara Harvard (alguns medievalistes d'aquesta institució eren Chandler R. Post, Arthur Kingsley Porter i Walter Cook) i Princeton, van mostrar un extraordinari interès per l'art medieval europeu, un interès, d'altra banda, interrelacionat amb l'emergència i la formació de la història de l'art americana com una nova disciplina acadèmica. En aquest context, l'art medieval ${ }^{41}$ va esdevenir un coneixement estel-lar, i aquesta fascinació va anar acompanyada de l'arribada d'importants tresors medievals als Estats Units, així com de la celebració d'exposicions dedicades a l'art d'aquest període. Un exemple en aquest sentit és la memorable mostra d'objectes medievals, organitzada l'any i9 4 pel Metropolitan 
Museum of Art, procedents de la col-lecció de John Pierpont Morgan ${ }^{42}$, la qual es convertiria en el primer nucli medieval d'aquest museu. Un altre fenomen, relacionat indirectament amb la nostra problemàtica, és el museu creat el I9I4 per l'escultor i agent d'art George Grey Barnard $^{43}$. El Barnard Cloisters, situat a Washington Heights, a Nova York, aglutinava una important collecció de peces medievals. Cal subratllar que aquest recull va constituir en el seu temps la col-lecció més important d'escultura romànica i gòtica de l'Amèrica del Nord i potser l'única comparable amb la d'Isabella Stewart Gardner ${ }^{44}$, exposada a Fenway Court, Boston. En aquest sentit cal recordar que James J. Rorimer ${ }^{45}$ va fer un encertat retrat de George G. Barnard:

The initial imagination and dedication leading up to this achievement were those of the sculptor George Grey Barnard, one of the most romantic and rugged collectors of recent time. He was the first person to recognize the importance of such a museum of medieval art, and we owe him gratitude and admiration for bringing together the sections of cloisters that made possible the reconstruction of the four cloisters that are the nucleus of our collection.

Com és conegut, el museu de Barnard va ser adquirit el 1925 per John Davison Rockefeller, Jr. (I 874-I960), financer i home de negocis, alhora que reconegut filantrop i munificent benefactor del Metropolitan Museum of Art. Per aquells anys, Rockefeller va comprar els terrenys del Fort Tryon Park, els quals, el 1930, després de laborioses negociacions, va regalar a la ciutat de Nova York espai on s'aixecaria el futur museu dels Cloisters ${ }^{46}$, dedicat a les arts medievals i construit per Charles Collens (I 873-1956), arquitecte del potent financer americà. Els Cloisters van obrir oficialment les seves portes el Io de maig de I 938 , justament un any després de la mort de John D. Rockfeller i un mes després de la de George G. Barnard, l'abril de 1938 . Nogensmenys, la inauguración ${ }^{47}$ d'aquest museu també va significar la presentació oficial dels dos grans i magnífics frescs del monestir de San Pedro de Arlanza que el museu havia adquirit: el lleó (figura I4) i el drac alat o serpent (figura I 5 ).

\section{L’arribada de Josep Gudiol i Ricart als Estats Units}

Josep Gudiol i Ricart tenia al voltant de vint-isis anys quan va fer el seu primer viatge a Nova

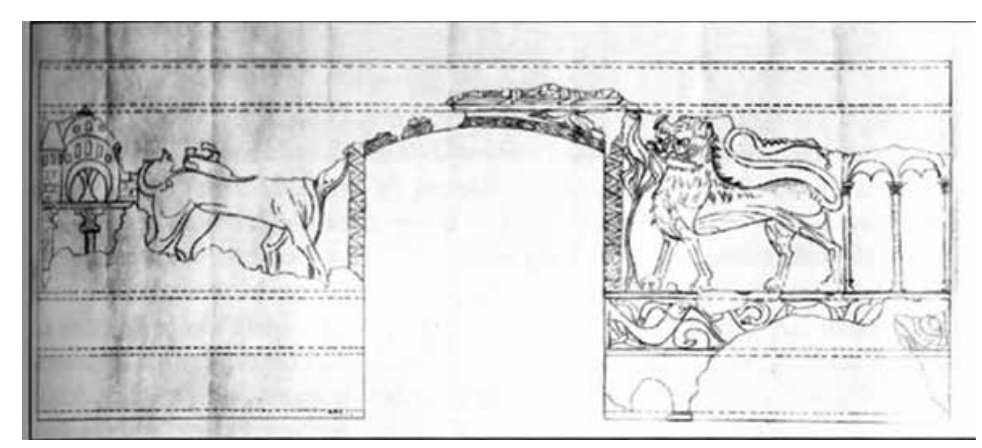

Figura 7.

Josep Gudiol i Ricart. Esquema compositiu del mur oriental de la Torre del Tresor: a la dreta, el lleó i, a l'esquerra, un fragment d'un felí. Frick Art Reference Library.

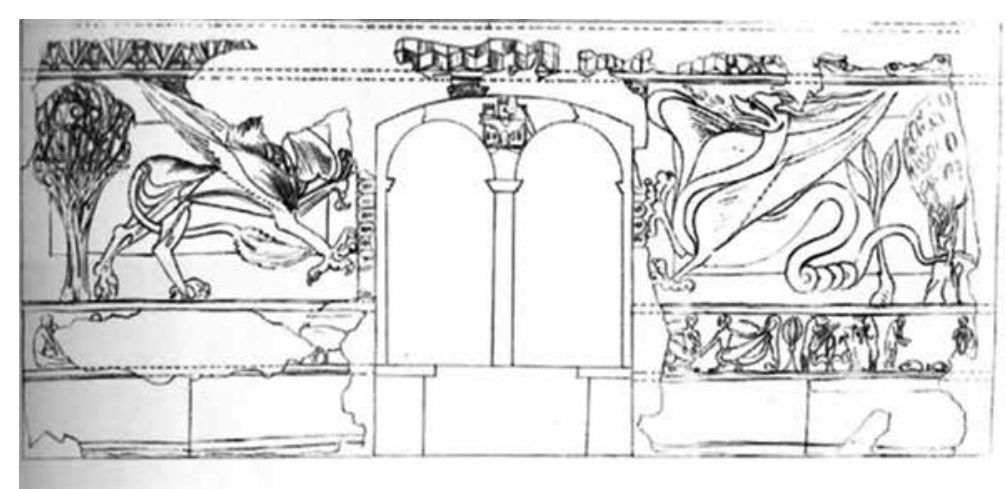

Figura 8.

Josep Gudiol i Ricart. Esquema compositiu del mur meridional de la Torre del Tesoro a la dreta, el drac alat, i a l'esquerra, el griu. Frick Art Reference Library.

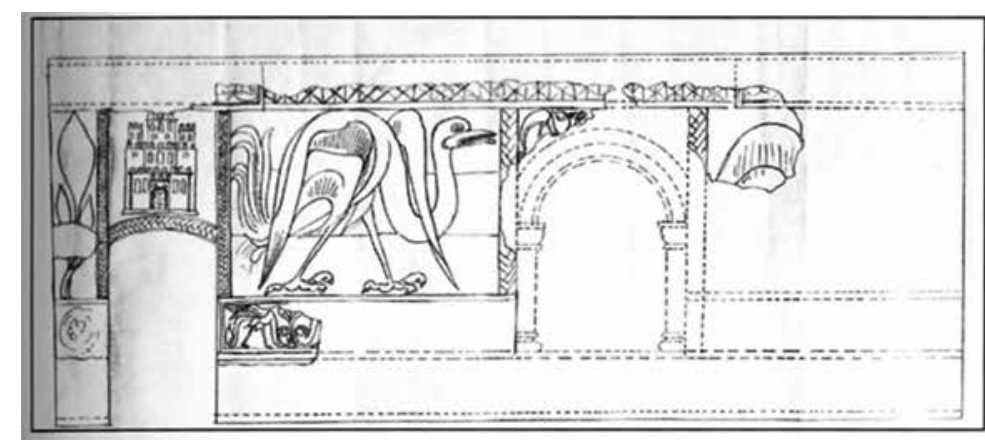

Figura 9.

Josep Gudiol i Ricart. Esquema compositiu del mur septentrional de la Torre del Tesoro: a l'esquerra, un ocell monumental. Biblioteca de Frick Art Reference Library.

York. Va arribar ${ }^{48}$ a primers d'agost del 1930 a la gran urbs americana amb la intenció de vendre els frescs de San Pedro de Arlanza. La seva principal targeta de presentació als Estats Units, com ell mateix reconeixia, va ser que era el nebot de Josep Gudiol i Cunill, l'influent i prestigiós director del Museu Episcopal de Vic, que era conegut principalment per Walter W. S. Cook i Chandler R. Post, medievalistes que tindrien una gran influència en la trajectòria del jove Gudiol i Ricart. Precisament ell, en una carta a la seva família, es referia a la notorietat del seu oncle als Estats Units dient ${ }^{49}$ : 


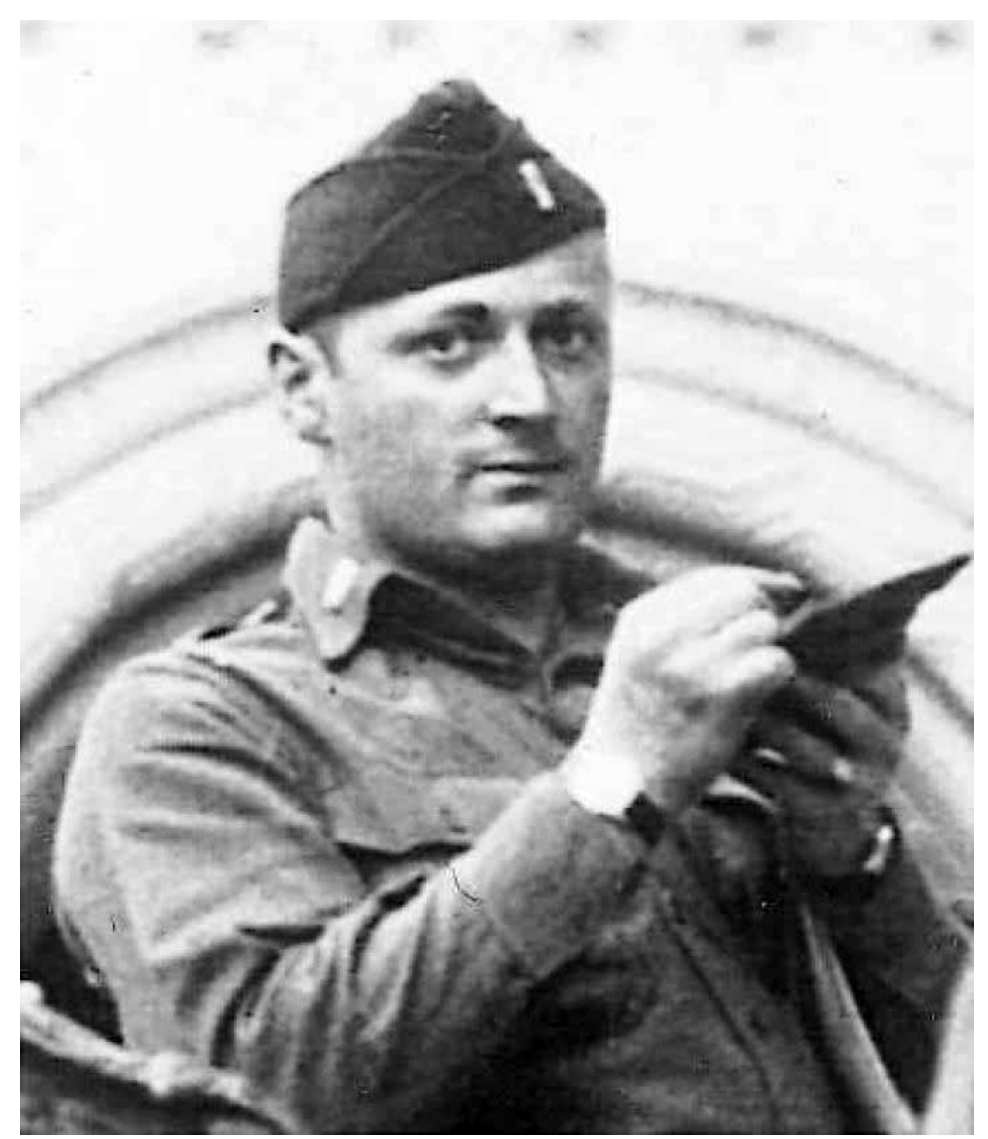

Figura 10.

James Joseph Rorimer (<https://alchetron.com/James-Rorimer $>$ ). va que l'any anterior els havia vist a Espanya i que estaven en molt bones condicions. Acabava la carta dient que considerava Josep Gudiol un jove extremament intel-ligent $i$ que gaudia de molts contactes amb el món de l'art a Espanya. Animava Sachs a conèixer-lo personalment $\mathrm{i}$ hi afegia que Gudiol tenia un coneixement inusualment ampli de l'art medieval i que li estaria molt agraït si li mostrava els objectes d'art hispànic que custodiava el Fogg Art Museum. Segons aquest document, els papers estaven clars. Josep Colominas era el propietari de les pintures i Gudiol actuava com el seu agent als Estats Units, una situació també compartida per James Rorimer ${ }^{51}$ i recollida en el seu informe confidencial ${ }^{52}$ :

[...] it was possible for Sr. Colominas (an antiquarian from Barcelona), and others, to buy frescoes which are now in America.

Però, tal com es reflecteix a la bibliografia, el rol de cadascun no estava clar, atès que la majoria de les fonts consideren que Josep Gudiol és l'autor de les fotografies i dels diagrames d'Arlanza, molt poques li atribueixen la remoció ${ }^{53}$ dels frescs i poquíssimes, la copropietat de les pinture $^{54}$. La confusió, però, l'aclareix el mateix Gudiol $^{55}$ en designar-se, conjuntament amb Colominas, com un agent $\mathrm{i}$ copropietari dels frescs:

I, J. Gudiol, acting as agent and part owner of the Thirteenth-century frescoes from Arlanza, extend until the end of February the first option to the Metropolitan Museum of Art to buy frescoes at the Museum [...].

Obviant momentàniament aquesta qüestió, cal assenyalar que Josep Gudiol va tenir dos suports incondicionals als Estats Units. L'un va ser, com ja s'ha comentat, Walter Cook i l'altre, James Rorimer. Aquest, que el 1929 havia tingut l'oportunitat d'examinar els frescs d'Arlanza a casa de Gudiol a Barcelona, també li va obrir les portes del Metropolitan Museum of Art, com ell mateix refereix ${ }^{56}$ :

This agreement was reached between the late Mr. Robinson and myself following my trip to Spain where I first saw these frescoes at Gudiol's house. They had already been removed from Arlanza when I was there in I929.

Tanmateix, mentre es teixia l'operació d'aquesta importantíssima transacció, Gudiol no va perdre el temps i va vendre una seda hispanomoresca del segle XII per 350 dòlars al Metropolitan Museum of Art ${ }^{57}$. 


\section{Les sibil-lines negociacions en la venda dels murals}

El ro d'octubre de 1930 es va signar el document de compromís entre el director del Metropolitan Museum of Art, Edward Robinson, i Josep Gudiol i Ricart. En aquest document s'escripturava que oferia al museu la primera opció de compra dels murals i que es mantenia durant un període de dos mesos, amb un preu de 50.000 dòlars, xifra que es podria rebaixar a 45.000 dòlars. Aquesta quantitat també incloïa la restauració dels frescs i la instal-lació definitiva sota la batuta conjunta de la direcció del museu i la del mateix $\mathrm{Gu}-$ diol. També s'hi establia que els treballs no es perllongarien més enllà de tres mesos ${ }^{58}$. A més, l'esmentat document especificava que, després de l'arribada dels frescs a Nova York i d'efectuar els tràmits de la duana, el Metropolitan Museum of Art es comprometia a guardar-los dos mesos en els seus dipòsits, a més, manifestava que durant aquest període Josep Gudiol els podria mostrar a uns altres museus o colleccionistes interessats a comprar-los, però sempre amb el vistiplau de la direcció del museu.

Paral-lelament, James Rorimer ${ }^{59}$ va elaborar un informe confidencial valorant positivament la compra dels frescs per part del Metropolitan Museum of Art. El document començava amb una breu introducció històrica sobre el monestir de San Pedro de Arlanza. Seguidament explicava que després de la desamortització el cenobi no havia estat declarat monument nacional, fet que havia possibilitat la compra dels frescs, i referia:

[...] In 1928, J.Gudiol, a young architect who is the nephew of Dr. Gudiol, the noted archaeologist and Director of the Museum of Vich, removed the frescoes from Arlanza and remounted them [...].

James Rorimer també deia que el Metropolitan Museum of Art havia rebut la primera opció de compra i que ningú els havia vist des que van ser remoguts. Després comentava que les pintures, encara que incompletes i descolorides, estaven en bones condicions. Indicava que els desperfectes d'un parell de panells havien estat restaurats lleument per tal de preservar-ne l'estat original. A més, valorava molt positivament l'existència del procés fotogràfic realitzat per Gudiol, perquè constituïa un excel-lent testimoni de l'originalitat i la conservació dels frescs. També considerava que la sala de la torre del tresor, que identificava com la capitular del monestir, podria ser fàcilment reconstruïa als Cloisters. Finalment, i per tal d'aconseguir una valoració positiva per part del museu, citava Post, un pres- tigiós professor i una reconeguda autoritat en el camp medieval ${ }^{60}$ :

Professor Chandler Rathfon Post of Harvard University, in the most recent, and authoritative book on Spanish Painting, says that the top of the room is adorned by the relics of a friese of various large, magnificently conceived and beautifully executed monsters, marked by the usual grotesque imagination of the Romanesque époque in the creation of such prodigious fragments of fancy [...] The frescoes have been published by several other important scholars of Spanish art (see bibliography). There is a divergence of opinion as to whether the frescoes are of the late twelfth or early thirteenth century, but it is reasonable to believe that they were painted about I220. The animals and monsters form a cycle unique in Spanish fresco painting. In beauty and boldness of design and in richness of color they are unsurpassed by any Spanish frescoes still extant.

El 6 de gener de 193 I, Rorimer ${ }^{61}$ recordava a Joseph Breck ${ }^{62}$, conservador del Metropolitan Museum of Art, que aquesta institució en tenia la primera opció de compra i que acabava el 22 de febrer de I93 I. Així mateix, li deia que els murals valien 45.000 dòlars, quantitat que n'incloïa la restauració i la instal-lació. I assenyalava, també, que en aquest preu no hi estava comptada la pedra de la finestra que hi havia a la torre del tresor d'Arlanza, però que si els interessava es podria comprar a Santander per 2.000 dòlars.

Els esdeveniments es van precipitar. Al cap de pocs dies, el 27 de gener de I93 I, Josep Breck ${ }^{63}$ va contactar amb John D. Rockefeller, gran mecenes del museu, i li va parlar de l'extraordinària importància que tenien els murals d'Arlanza i de la conveniència de comprar-los. Breck li explicava que va quedar impressionat quan va veure les fotografies i que no va dubtar a posar-se en contacte amb els propietaris per tenir-los on approval, és a dir, per examinar-los per si interessava comprar-los. També li feia saber que les pintures ja es trobaven al seu despatx i referia a Rockefeller que el preu dels cinc grans panells, així com de les seccions inferiors corresponents, era de 50.000 dòlars, però que Josep Gudiol n'havia fet una rebaixa de 5.000 dòlars, amb la qual cosa tot el conjunt pictòric valia 45.000 dòlars.

Joseph Breck pensava que aquest preu era molt acceptable i considerava que els frescs eren uns exemplars esplèndids $\mathrm{i}$ únics de la pintura medieval castellana, sobretot si es comparava amb els I 20.000 dòlars que el Museu de Belles Arts, de Boston, havia pagat per les dues escenes de San Baudelio de Berlanga (Sòria), o els 85.000 


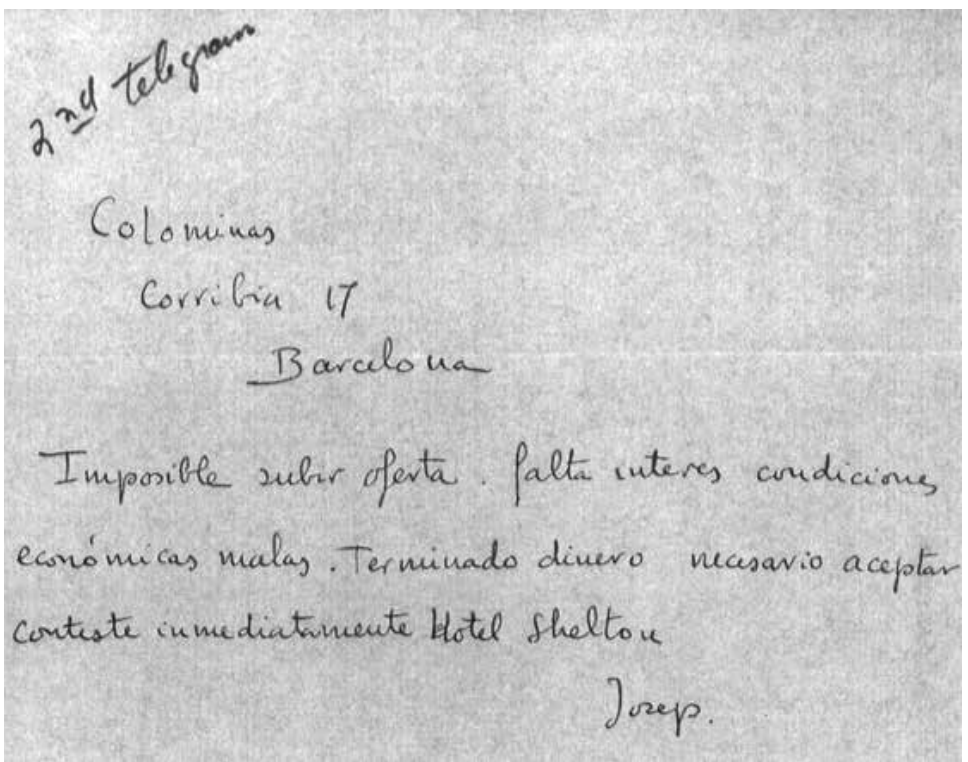

Figura 11.

Cablegrama de Josep Gudiol a Josep Colominas. Nova York, Metropolitan Museum of Art.

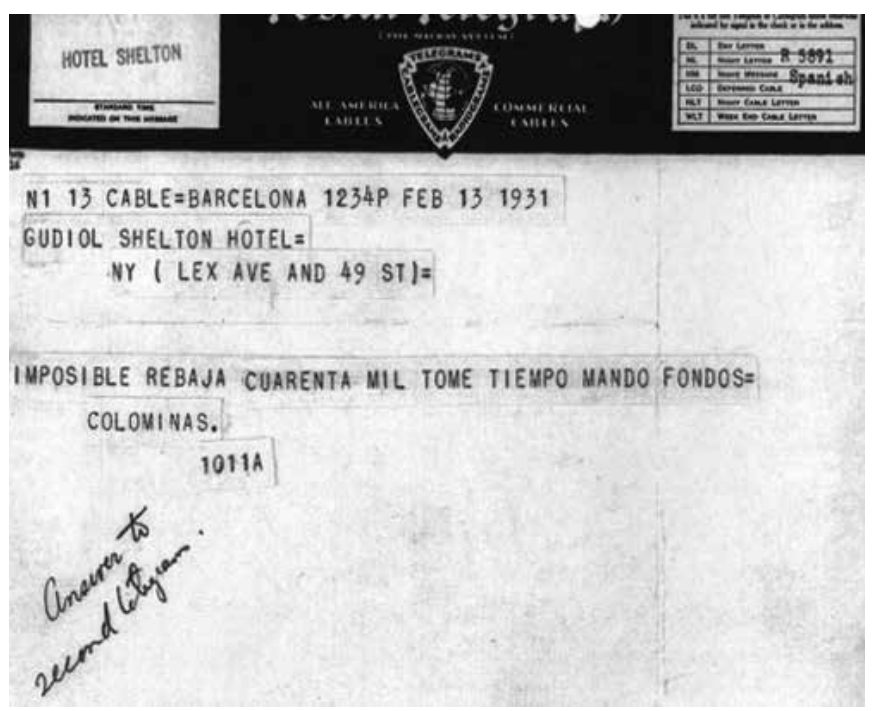

Figura 12.

Cablegrama de Josep Colominas a Josep Gudiol. Nova York, Metropolitan Museum of Art.

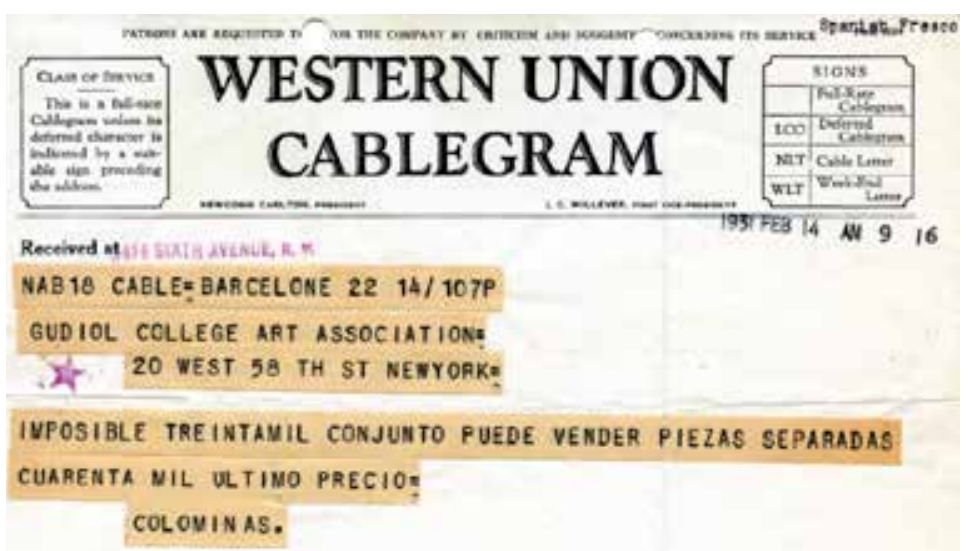

Figura 13.

Cablegrama de Josep Colominas a Josep Gudiol. Nova York, Metropolitan Museum of Art. dòlars abonats pel de Santa Maria de Mur (Lleida). Assenyalava que els frescs del cenobi castellà d'Arlanza eren iguals o superiors que els citats anteriorment i concloïa recordant que Josep Gudiol els n'havia ofert l'opció de compra fins al 2 I de febrer de I93I.

Al cap de pocs dies, John D. Rockefeller ${ }^{64}$ contestava a Joseph Breck comunicant-li que George Blumenthal ${ }^{65}$, president del Metropolitan Museum of Art, era de l'opinió que només calia comprar els que estaven en millors condicions de conservació, alhora que desaconsellava adquirir-ne la resta, argüint que ocuparien molt d'espai en el futur museu dels Cloisters. Tanmateix, i malgrat aquestes consideracions, Rockefeller estava disposat a comprar-ne tot el lot sencer, però va teixir una astuta actuació financera a fi de rebaixar-ne el preu. Amb aquesta finalitat, va recomanar a Breck que digués que, tot i que el museu estava meditant si els adquiria o no, ell estava intentant aconseguir uns 25.000 o 30.000 dòlars per tal d'obtenir les valuoses pintures. Seguint aquestes sibil-lines indicacions, Breck ${ }^{66}$ va oferir a Josep Gudiol, just l'endemà, el ro de febrer, entre 25.000 i 30.000 dòlars per tot el lot. Alhora es lamentava perquè entenia que la seva oferta representava una considerable rebaixa respecte del preu fixat inicialment $i$, com a excusa, adduïa la feble situació financera del museu. Davant d'aquesta lleonina contraoferta, Josep Gudiol $^{67}$ va enviar ràpidament un cablegrama al seu soci, Josep Colominas, explicant-li les condicions financeres del museu: «Imposible subir oferta, falta interés, condiciones económicas malas. Terminado el dinero. Necesario aceptar. Conteste inmediatamente. Hotel Shelton. Josep» (figura II).

La resposta de Josep Colominas ${ }^{68}$ va ser taxativa: «Imposible rebaja. Cuarenta mil. Tome tiempo. Mando fondos. Colominas» (figura I 2).

Al matí següent, el I4 de febrer de I93 I, Colominas $^{69}$ enviava un altre cablegrama a Josep Gudiol rebaixant el preu dels frescs a 40.000 dòlars, tot negant-se a vendre'ls per 30.000 dòlars i autoritzant-lo a desprendre's dels murals de manera separada, amb la idea d'aconseguir la suma fixada inicialment (figura 13 ).

Després de laborioses negociacions, el i6 de febrer de 193 I les dues parts van arribar a un acord, segons consta en el document signat per Josep Gudiol ${ }^{70}$ :

I, J. Gudiol, acting as agent and part owner of the thirteenth-century frescoes from Arlan$\mathrm{za}$, extend until the end of February the first option to the Metropolitan Museum of Art to purchase the frescoes under the following conditions: We will sell the two large panels, one with a lion, the other with a serpent, and 
the panels which go below them for 30.000 dollars. The price for the entire group of Arlan$\mathrm{za}$ frescoes, five large and ten small panels, is 40.000 dollars. I shall undertake only the transferal of the frescoes to aluminum, but I will not do the work of restoration except in so far as is necessary for final preservation. If the Museum should purchase the two panels alone, it is understood that I am to be allowed to keep the entire lot of frescoes in the Museum until my work of transferring is completed.

Mentrestant, Joseph Breck ${ }^{71}$ comunicava a John Rockefeller que, seguint les seves indicacions, havia ofert a Josep Gudiol entre $25.000 \mathrm{i}$ 30.000 dòlars, però que aquest no havia acceptat la venda del conjunt per aquesta quantitat. Davant d'aquesta situació, el Metropolitan Museum of Art va decidir finalment comprar els dos frescs que considerava millors, el del lleó (figura I4) i el del drac alat o serpent (figura i 5 ), així com els corresponents frisos inferiors, per un total de 30.000 dòlars, tot i que Breck encara va aconseguir rebaixar aquesta xifra a 28.000 dòlars.

A fi de segellar definitivament l'acord, el 24 de febrer de I93I, el Metropolitan Museum of Art va emetre una factura ${ }^{72}$ per la compra del lleó i del drac alat o serpent, així com dels frisos respectius, en la qual feia constar que eren els originals de San Pedro de Arlanza. A la factura hi apareixia el nom de Josep Gudiol com a agent, que, finalment, va pagar 28.000 dòlars, uns diners que es van girar al compte de Josep Colominas al Banc Alemany Transatlàntic, sucursal de Barcelona (figura I6).

D'altra banda, Josep Gudiol ${ }^{73}$ va estendre un document en el qual expressava la seva conformitat amb les condicions de venda, mentre que el Metropolitan Museum of Art $^{74}$ recordava que aquest havia de transferir els frescs als Cloisters $\mathrm{i}$ que es comprometia a guardar-ne la resta fins al 3 I de desembre de I93I.

Una vegada signats els pactes de la compra, Joseph Breck va comunicar a Robert Weeks de Forest $^{75}$, president del Metropolitan Museum of Art - que havia avançat els diners de l'operació-, que John D. Rockefeller ${ }^{76}$ ja havia pagat els frescs i que els havia regalat al museu, anunciant que, com en el cas d'altres donacions, no es faria publicitat dels frescs fins a la inauguració del museu dels Cloisters.

\section{Problemes després de la venda dels murals d'Arlanza}

La notícia de la transacció al Metropolitan Museum of Art va aixecar irades protestes a la Península, però també van crispar l'ambient uns crítics

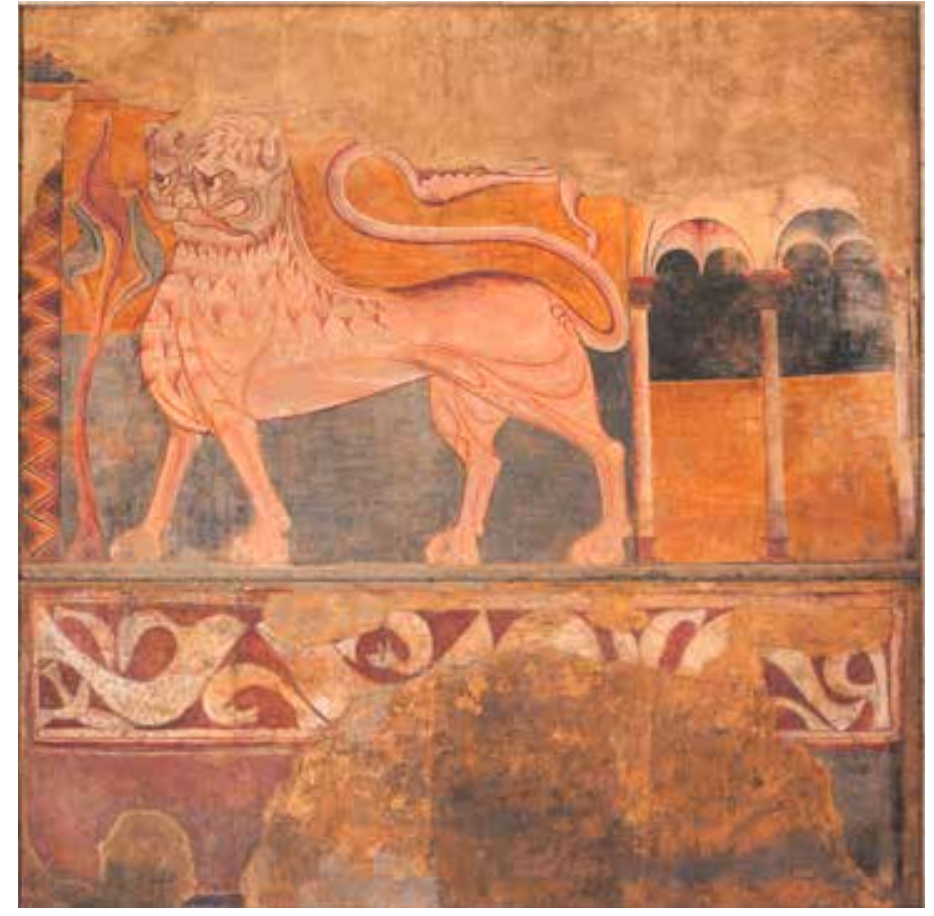

Figura 14.

Lleó de San Pedro de Arlanza. Nova York, The Cloisters.

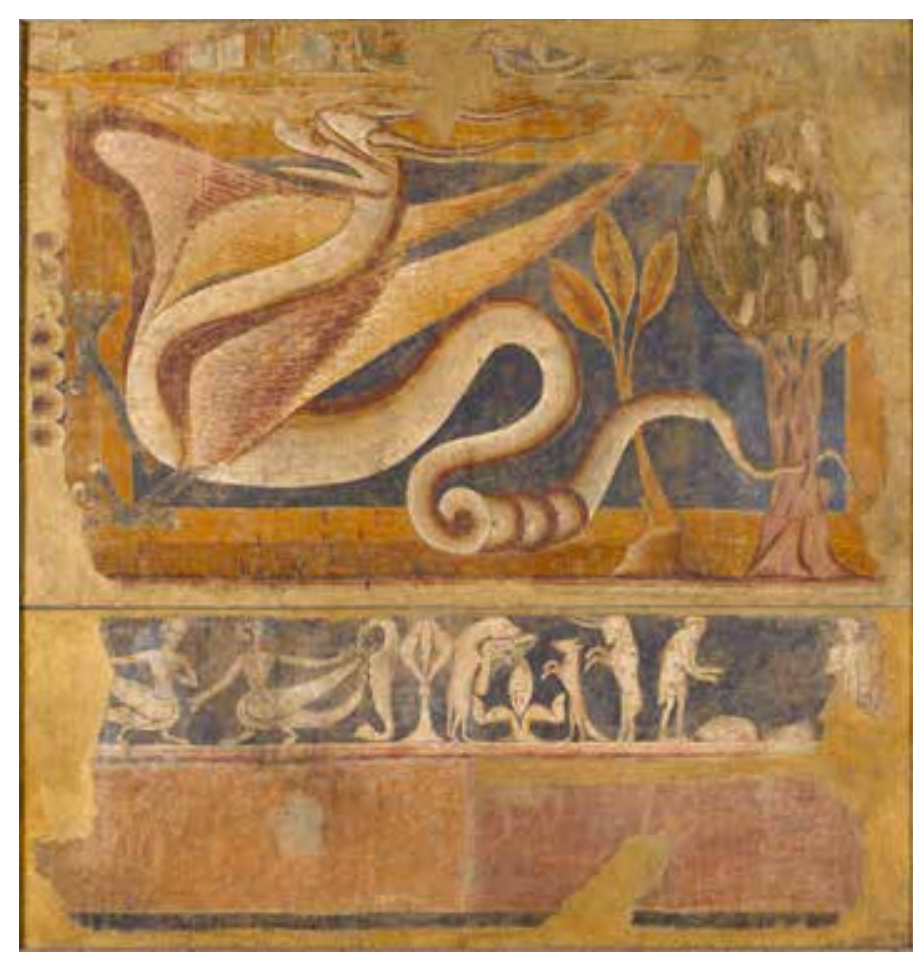

Figura 15.

Drac alat o serpent de San Pedro de Arlanza. Nova York, The Cloisters.

comentaris del medievalista Chandler R. Post que James J. Rorimer ${ }^{77}$ va considerar desafortunats. En aquest sentit, aquest va dir a Post que era convenient tractar la compra dels frescs discretament i recomanant que no parlés sobre l'adquisició dels murals ni a Espanya ni als Estats Units: 


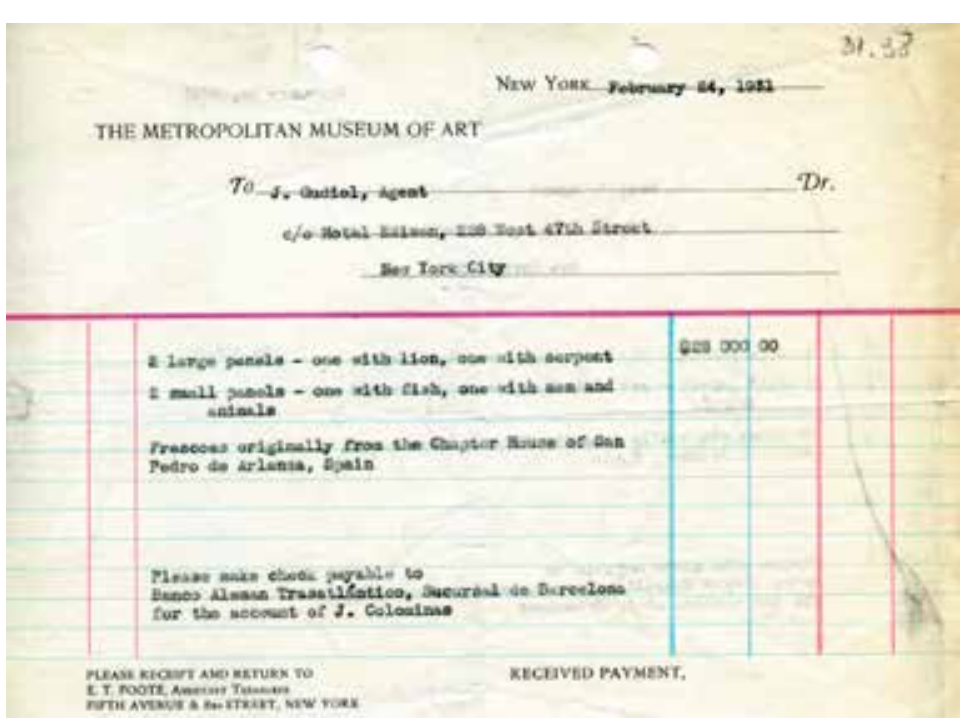

Figura 16.

Factura. Nova York, Metropolitan Museum of Art.

I have been thinking over the problem of the Arlanza frescoes. I am going to ask you, as a personal favor to me as well as out of regard for the Metropolitan Museum, not to speak in Spain or elsewhere about these frescoes. It is really a very serious matter, and we are desirous not to have it known that we have obtained some of these panels. Josep Gudiol, of whom you spoke, was not the owner of the frescoes, but merely employed to do certain work of transferal and to help us in dealings with certain of the owners.

Paradoxalment, i com es fa palès en aquest document, Rorimer - $\mathrm{i}$ malgrat les evidències proporcionades pel mateix Gudiol- insistia que aquest no era el propietari dels frescs, sinó tan sols l'agent de la venda, afirmava que el Metropolitan Museum of Art havia comprat les pintures legalment i que aquestes havien sortit correctament d'Espanya. Rorimer ${ }^{78}$ tam- $^{\prime}$ bé es lamentava de la desafortunada situació que Post havia creat i deia a Josep Gudiol que li remetia la carta que el medievalista havia escrit perquè tingués constància de la seva lleialtat.

\section{El retorn de Josep Gudiol i Ricart a Nova York}

A finals d'octubre de I93 I, Gudiol va tornar a Nova York perquè el 3 I de desembre finalitzava el termini de la custòdia de les pintures al Metropolitan Museum of Art. Tanmateix, aquest no era l'únic objectiu que calia complir, l'altre era trobar possibles compradors per a la resta dels murals d'Arlanza. Una vegada més, James
Rorimer $^{79}$ va oferir el seu suport a Gudiol pensant que el Metropolitan podria estar interessat a comprar-los, i amb aquest propòsit es va tornar a dirigir a Joseph Breck:

[...] Should I hear from Gudiol tonight, I will suggest, if he is desirous of selling the ramaining frescos or any material of considerable importance $[\ldots]$.

Llavors, Breck ${ }^{80}$, davant d'aquesta nova oferta, va contactar de nou amb George Blumenthal i li comunicà que Josep Gudiol n'havia rebaixat el preu. Hi afegia que les pintures que aleshores s'oferien no estaven en tan bones condicions com les que s'havien comprat anteriorment. Però els directius del museu tenien clar que no volien reproduir als Cloisters la torre del tresor de San Pedro de Arlanza i, en conseqüència, van declinar la nova oferta. No obstant això, i malgrat aquesta negativa, Josep Gudiol va continuar mantenint bona relació amb el Metropolitan Museum a través de la venda de les seves fotografies ${ }^{81} \mathrm{i}$ potser uns altres objectes d'art. Particularment, va conservar estrets lligams amb James Rorimer ${ }^{82}$, que al març de 1934 li va anunciar una propera visita a Barcelona per veure objectes d'art i visitar José Ferrándiz ${ }^{83}$, especialista en ivoris, tèxtils i catifes. Mentrestant, la resta de les pintures continuaven a Nova York esperant una bona ocasió per ser venudes, la qual va arribar quan es va formalitzar la venda del fantàstic ocell d'uns dels panells al Fogg Art Museum, de la Universitat de Harvard.

\section{L'arribada de la resta dels frescs a Catalunya}

Entre els anys r936 i r939, Espanya es dessagnava en un cruel conflicte bèl-lic $\mathrm{i}$ la victòria del bàndol franquista el I 939 va provocar l'exili de notables personalitats, entre les quals hi havia Josep Gudiol. Amb el suport de Walter W. S. Cook, va marxar primer a França i després als Estats Units, i tornà definitivament a Barcelona el r94 I. Com és conegut, una de les tràgiques conseqüències de la guerra va ser la destrucció de molts edificis i l'espoli d'una gran quantitat de béns i col-leccions. A causa d'aquestes terribles circumstàncies, molts tresors artístics van buscar refugi en diversos museus de Catalunya ${ }^{84}$, i seguint aquesta tònica Josep Colominas va resguardar la resta dels fragments de San Pedro de Arlanza al Museu Arqueològic de Catalunya. La situació va ser desvelada per un informe realitzat el 7 de febrer de I940 per Luis Monreal Tejada ${ }^{85}$, comissari franquista de la zona de Llevant, en el qual explicava: 


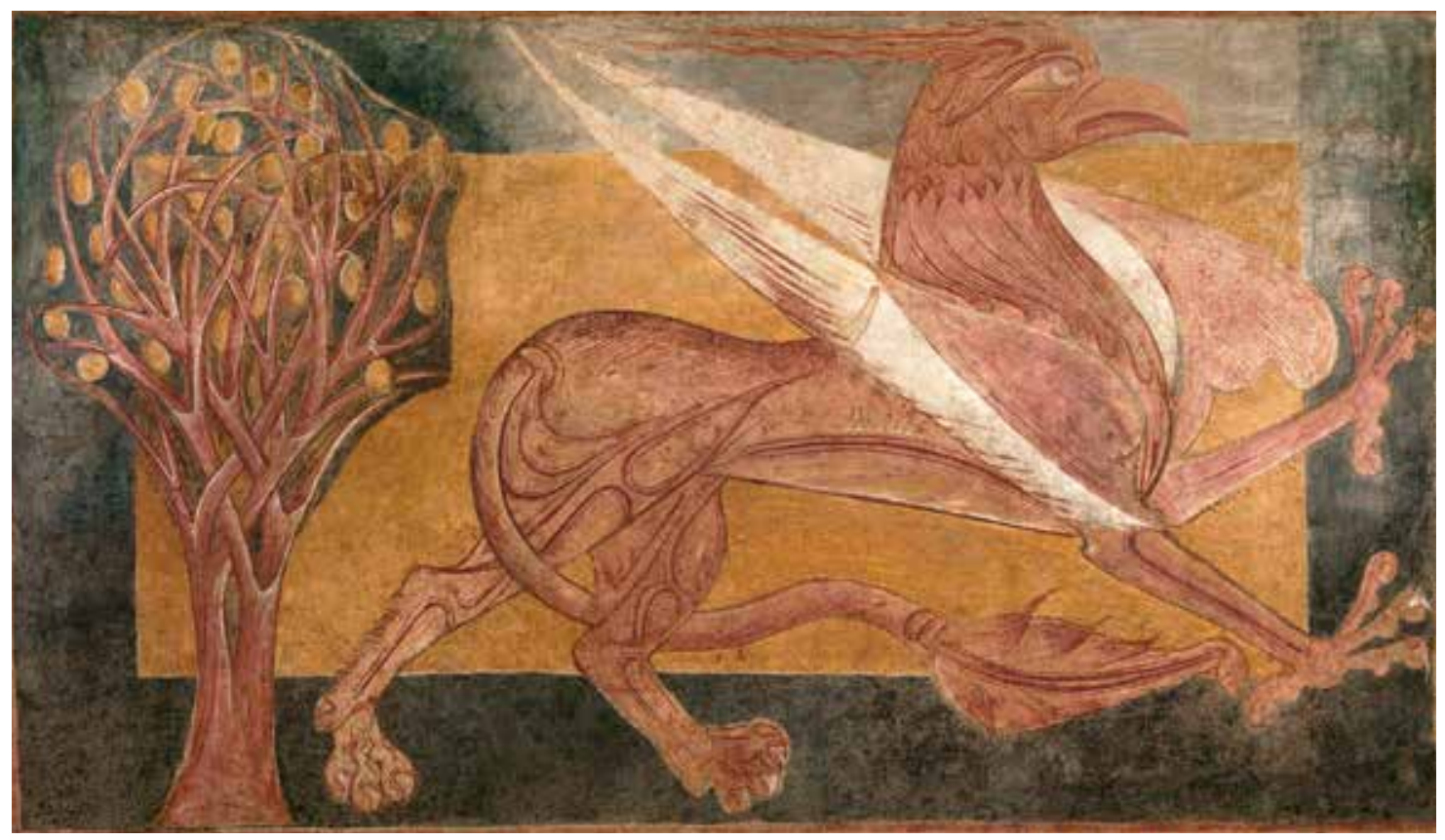

Figura 17.

Griu de San Pedro de Arlanza. Barcelona, Museu Nacional d'Art de Catalunya.

Dichas pinturas fueron adquiridas por $\mathrm{Gu}-$ diol (arquitecto rojo, hoy en el extranjero) y Colominas (funcionario del Museo Arqueológico de Barcelona). Según me ha manifestado este último, pagaron por la adquisición dos mil pesetas. La totalidad de las pinturas así adquiridas es la que puede verse en los diseños que se acompañan de la forma en que estaban instaladas tales pinturas murales en su origen. Parte de las pinturas (las más importantes) fueron vendidas en Norteamérica. El resto está actualmente almacenado en el $\mathrm{Mu}$ seo Arqueológico de Barcelona y las tiene el Sr. Colominas en venta, pues asegura que actualmente son de su exclusiva propiedad [...].

Com és evident, aquest document fa referència a dues qüestions principals. La primera és la relativa al preu dels frescs d'Arlanza. Josep Colominas va declarar al comissari franquista que s'havien pagat 2.000 pessetes pels frescs, una quantitat molt inferior a les 10.000 pessetes demanades inicialment per la família Barbadillo l'any 1924; una quantitat que, si fos certa, hauria representat, encara més, l'obtenció d'uns beneficis extraordinaris per part de Gudiol i Colominas. La segona qüestió fa referència a la propietat de les pintures. L'informe manifesta clarament que eren de Josep Colominas i de Josep Gudiol, fet que, d'altra banda, concorda amb alguns dels documents examinats del Metropolitan Museum of Art. Però també manifesta que les restes dels frescs d'Arlanza dipositats al $\mathrm{Mu}$ seu Arqueològic eren propietat de Josep Colo- minas, una afirmació que potser va ser deguda a l'exili de Josep Gudiol o potser al fet que els dos socis ja s'havien repartit les restes d'Arlanza, $i$ les que estaven estotjades al Museu Arqueològic eren les que pertanyien a Josep Colominas. Els fets posteriors demostrarien com a plausible aquesta segona hipòtesi, perquè el 29 de novembre de I 943 Josep Colominas venia el griu (figura I7) al Museu Nacional d'Art de Catalunya, i aquest mateix any Josep Gudiol també venia a aquest museu el castell, dos ocells i els dos simis entrellaçats $^{86}$. Al cap de molts anys, el 1973, Josep Gudiol ${ }^{87}$ va fer un donatiu de diversos fragments, entre ells un felí, a la mateixa institució, però, tanmateix, el puzle encara no estava complet. Hi mancava una peça més.

L'any 1952 Josep Gudiol ${ }^{88}$ havia venut un altre fragment d'Arlanza, les sirenes ocells (figura I8), al preeminent col-leccionista Antonio Gallardo Ballart ${ }^{89}$, que l'any 2015 va donar-lo, junt amb altres magnífiques obres, al Museu Nacional d'Art de Catalunya en concepte de pagament d'impostos i drets de successió.

\section{Cloenda}

Finalment, i com a colofó, vull recordar que l'espina dorsal d'aquest treball ha estat l'exhumació i la interpretació de fonts inèdites provinents dels arxius del Metropolitan Museum of Art, de Nova York referents al comerç de l'art. Documents que han permès conèixer detalladament les dramàtiques vicissituds del procés de com- 


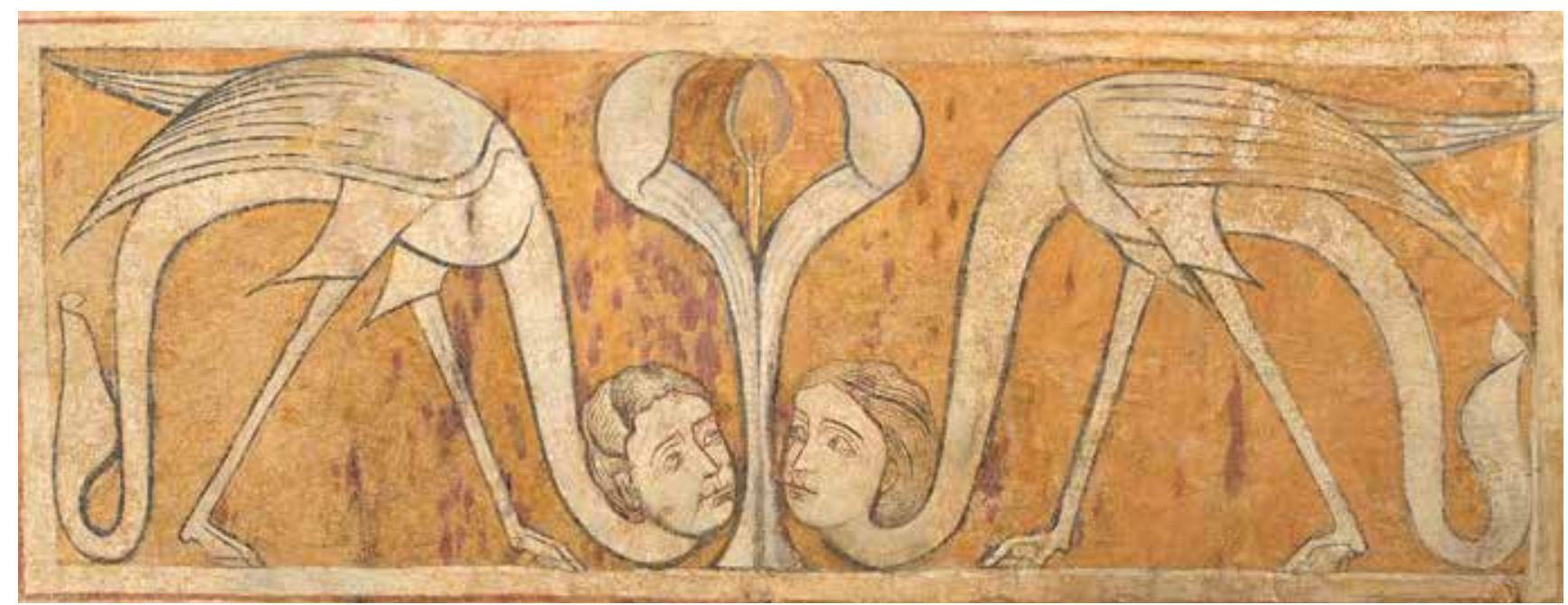

Figura 18.

Sirenes ocells de San Pedro de Arlanza. Barcelona, Museu Nacional d'Art de Catalunya.

pravenda dels frescs de la Torre del Tesoro del monestir de San Pedro de Arlanza, el seu procés de desmembrament, així com la pèrdua dels propis signes d'identitat. Uns fets que, en gran part, s'expliquen per les particulars circumstàncies socioeconòmiques $\mathrm{i}$ culturals existents a Espanya al primer terç del segle Xx i també per les especials vicissituds culturals que impulsaren el creixe- ment exponencial de les col-leccions públiques i privades nord-americanes. D'altra banda, també cal subratllar que aquests desconeguts documents han permès focalitzar l'atenció al voltant de Josep Colominas i Roca i de Josep Gudiol i Ricart, i conèixer com van aconseguir fer un negoci fabulós en les aigües de vegades procel-loses i, molt sovint, turbulentes del comerç de l'art. 
* Aquesta recerca ha estat possible gràcies a l'amabilitat de la secció arxivística del Metropolitan Museum of Art i especialment d'Adrianna Slaughter, la Thomas J. Watson Library del mateix museu, així com a la bona predisposició dels arxius dels Cloisters. Vull manifestar la meva gratitud a Audrey Loberfeld, Ellen Prokop i Sonia Agnew, de la Frick Art Reference Library, per l'ajut brindat. Així mateix, també vull deixar constància de les generoses $i$ oportunes indicacions de Jonathan Brown i de Robert Maxwell, professors de l'Institute of Fine Arts de la New York University. També el meu agraïment a Robert W. Hoge, Curator Emeritus de l'American Numismatic Society; Manuel Antonio Castiñeiras, de la Universitat Autònoma de Barcelona; Lourdes de San José i Alicia Brosa, de la Universitat de Barcelona; María José Martínez Ruiz, de la Universitat de Valladolid.

1. Alguns dels autors que s'han ocupat específicament del monestir d'Arlanza i les seves pintures han estat Rodrigo AMADOR DE LOS Ríos y Fernández Villalta (1896), Las ruinas del Monasterio de San Pedro de Arlanza en la provincia de Burgos, Madrid, Imprenta de los Hijos de M. G. Hernández; Luciano Huidobro (1927), «El monasterio de S. Pedro de Arlanza y su primer compendio historial, inédito", Boletín de la Comisión Provincial de Monumentos Históricos y Artísticos de Burgos, 20, p. 211-214; Manuel GómEZ Moreno (1925), «Pinturas murales en San Pedro de Arlanza», Boletín de la Real Academia de la Historia, 86; Charles J. Kunn (1928), «Notes on some Spanish frescoes», a Art Studies: Medieval Renaissance and Modern, Cambridge, Harvard University Press, p. 123135; María Elena Gómez Moreno (1947), Mil joyas del arte español, Barcelona, Instituto Gallach de Librería y Ediciones, p. 160; Joan SuREdA (1985), La pintura románica en España: Aragón, Navarra Castilla-León y Galicia, Madrid, Alianza Editorial, p. 390; «The frescoes of San Pedro de Arlanza», a Elizabeth C. PARKER (ed.), The Cloisters: Studies in Honor of the Fifteenth Anniversary, Nova York, Metropolitan Museum of Art, 1992, p. 86-109; Luís A. GraU Lово (1996), Pintura románica en Castilla y León, Valladolid, Consejería de Educación y Cultura, p. 165; Walter CaHN (2000), «The frescoes of San Pedro de Arlanza», a Studies in Medieval Art and Interpretation, Londres, Pindar, p. 306; Enciclopedia del Románico en Castilla y León, Aguilar de Campoo, Fundación Santa María la Real, Centro de Estudios del Románico, 2002, IV, p. 2365; María José Martínez Ruiz (2008), La enajenación del patrimonio en Castilla y León, 1900-1936, Salamanca, Junta de Castilla y León, Consejería de Cultura y Turismo, p. 92; El esplendor del románico: Obras maestras del Museu Nacional d'Art de Catalunya, Madrid, Fundación Mapfre, 2011; Montserrat PAGÈs Paretas (2012), «Les pintures de San Pedro de Arlanza i els bestiaris anglesos", a Rosa Alcoy (ed.), Contextos 1200-1400: Art de Catalunya $i$ art d'Europa meridional en dos canvis de segle, Barcelona, Publicacions de la Universitat de Barcelona, p. 213-228; Montserrat Pagès I PARetas (2012), Pintura mural sagrada $i$ profana del romànic al primer gòtic, Barcelona, Abadia de Montserrat; María José Martínez Ruiz (2013), «La venta y expolio del patrimonio románico de Castilla y León: El caso de las pinturas murales», a Pedro Luis Huerta Huerta (coord.), La diáspora del románico hispano: De la protección al expolio, Aguilar de Campoo, Fundación Santa María la Real, p. 46; Immaculada Socias BATET (2016), «Les pintures murals de San Pedro de Arlanza al museu dels Cloisters de Nova York», a Agents $i$ comerç d'art: Noves fronteres, Gijón, Trea; José Luis SENRA (2018), «Y vivía entre las fieras, pero los ángeles le servían: Poder y representación abacial en el Monasterio de San Pedro de Arlanza», a Irene Gonzalez Hernando i Alexandra Uscastescu (eds.), En busca del saber: Arte y ciencia en el Mediterráneo medieval, Madrid, Universidad Complutense, p. 333 i s., i José Luis Hernando GarriDO (2018), «Espacios para la penitencia y ámbitos para la reclusión en el monasterio medieval», $E l$ monasterio medieval como célula social y espacio de convivencia, Aguilar de Campoo, Fundación Santa María la Real.

2. La desamortització es va iniciar a la fi del segle xviri $i$ es va desenvolupar sobretot a la primera meitat del segle XIx. El procés va consistir a posar al mercat, prèvia expropiació forçosa i mitjançant una subhasta pública, les terres $\mathrm{i}$ els béns que es trobaven en poder de l'Església i dels ordes religiosos, així com també les terres comunals dels municipis. Una de les desamortitzacions més importants va ser la duta a terme per Juan Álvarez Mendizábal, que el 1835 va decretar la supressió dels ordes monacals i militars. Les lleis següents serien, simplement, un des- envolupament del decret d'octubre del 1835. Així, el 19 de febrer del 1836 es va legislar la venda dels béns immobles dels monestirs i el 8 de març del 1836 se'n va estendre la supressió a tots els monestirs i congregacions masculines. Es pot ampliar aquesta qüestió a Germán Rueda Hernanz et al. (1986), La desamortización de Mendizábal y Espartero en España, Madrid, Cátedra, i Francisco Martí GilaBERT (2003), La desamortización española, Madrid, Rialp.

3. Elías Tormo Monzó (18691957) va publicar una extensa obra sobre art i arqueologia. Se'n poden consultar les consideracions sobre San Pedro de Arlanza a les actes de la Real Academia de Bellas Artes de San Fernando, 9 de novembre de 1924, f. 399.

4. Vicente LAMpÉrez (1909), Historia de la arquitectura cristiana española en la Edad Media según el estudio de los elementos y los monumentos, Madrid, Espasa Calpe, II, p. 159.

5. Julien Chappée (1912), «Arlanza découverte de peintures", Revue de l'Art Chrétien, 62, París, p. 380-381. Al final d'aquest article Luciano Huidobro, corresponsal de la revista, proporcionava també diverses informacions complementàries sobre els frescs.

Traducció de l'autora: «[...] La nau era una muntanya de runa. La sala capitular no té sostre i la decoració de guix feta al segle xvir cau gradualment. Sota aquests revestiments hi ha magnífics murals en perfecta conservació. Ara el més visible es un gran lleó, atribut de l'evangelista sant Marc. També podem veure un fragment del bou de sant Lluc. Seria molt desitjable que aquestes pintures fossin arrencades abans de la seva desaparició definitiva [...]. Les pintures van ser fotografiades $i$ hem d'esperar que això signifiqui un nou començament».

6. Sobre l'actuació d'aquestes institucions es pot consultar, entre d'altres, Manuel Gómez-Moreno (1925), «Pinturas murales en San Pedro de Arlanza», Boletín de la Real Academia de la Historia; Real Academia de Bellas Artes de San Fernando, actes de la sessió ordinària del 6 d'octubre de 1924, f. 400. Les actes també es poden consultar en línia a: <http://www. cervantesvirtual.com/portales/ bellas_artes_san_fernando/ partes/235915/actas-de-lassesiones-particulares-ordinariasgenerales-extraordinariaspublicas-y-solemnes-de-la-real- 
academia-de-bellas-artes-de-sanfernando-41/17>, i també María José Martínez Ruiz (2008), La enajenación del patrimonio en Castilla y León, 1900-1936, p. 92-106; «La venta y expolio del patrimonio románico de Castilla y León: El caso de las pinturas murales», a La diáspora del románico hispano: De la protección al expolio. Aguilar de Campoo, Fundación Santa María la Real, 2013, p. 55.

7. Manuel Gómez-Moreno, ibídem, p. 14.

8. Real Academia de Bellas Artes de San Fernando, actes de la sessió ordinària del 6 d'octubre de 1924 , f. 400 .

9. Manuel Gómez-Moreno Martínez (1870-1970) va ser un arqueòleg i historiador de l'art. Sobre aquest autor es pot consultar l'article «Pinturas murales en San Pedro de Arlanza», Boletín de la Real Academia de la Historia, 1925, 86, p. 14 is.

10. Vegeu Elias Tormo Monzó (1869-1957), Real Academia de Bellas Artes de San Fernando, actes de les sessions del 9 de novembre de 1924, f. 399.

11. Narciso Sentenach Cabañas (1853-1925), historiador, crític d'art i arqueòleg.

12. L'any 1926, el College Art Association (CAA) va promoure una fundació a fi d'impulsar la investigació de l'art hispànic. Aquesta institució també pretenia establir una escola americana d'estudis hispànics a Madrid, com ja havia fet a Itàlia i a Grècia. Al davant d'aquest projecte hi havia Walter W. S. Cook, professor de la New York University i membre del College Art Association. Sobre aquesta institució es pot consultar el text següent: Susan BALL (ed.) (2011), The Eye, the Hand, the Mind: 100 Years of the College Art Association, Nova York, The College Art Association \& Rutgers. The State University of New Jersey.

13. Walter W. S. Cook (Boston, 1888-1962) va ser un dels primers investigadors d'història medieval als Estats Units. Es va graduar a la Universitat de Harvard i el 1919 es va doctorar en art medieval hispànic, fet que el va obligar a passar llargues temporades a Catalunya i a Espanya. La seva tesi doctoral es va titular Romanesque Panel Painting in Catalonia, Universitat de Harvard, 1924, i va ser dirigida per Chandler R. Post. El 1926 va ingressar com a professor a la Universitat de Nova York, circumstància que no li va impedir realitzar viatges freqüents a Europa i Espanya per tal de dur a terme la seva investigació com a membre de la Secció d'Art Espanyol del College Art Association (CAA). Cook va ser també el director de l'Institute of Fine Arts de la New York University, institució que entre 1932 i 1953 va acollir reconeguts professors alemanys perseguits pels nazis, com ara, per exemple, Erwin Panofsky, Max Friedlander, Martin Weinberger, Henri Focillon, Otto Pacht, o també Josep Gudiol i Ricart, que fugia de la repressió franquista.

14. Walter W. S Cook (1929), «Unknown Romanesque Frescoes in Castile», Parnassus, 1(2) (15 de febrer), p. 14 i s.

15. Walter W. S. Соок (1929), «Romanesque Spanish Mural Painting», I, The Art Bulletin, College Art Association, 11(4) (desembre), p. 327-356.

16. Ibídem, 1929.

17. Es pot consultar el «Discurso del Conde de Romanones», a Nuestro patrimonio artístico; «Sesión en la Academia de Bellas Artes», La Voz (26 d'octubre de 1929); «El Tesoro artístico nacional: Real Academia de Bellas Artes», La Vanguardia (26 d'octubre de 1929); «Final de Arlanza», Turismo-Viajes, Visita de Castilla. El Sol (10 de novembre de 1929); "Nuestro patrimonio artístico", La Voz (26 d'octubre de 1929); «Romanesque Frescoes Discovered in Castille», The Art News (7 de gener de 1929).

18. Eduardo de Ontañón Levantini (1904-1949) va néixer a Burgos. $V a$ ser un escriptor, periodista $i$ editor que, en acabar la Guerra Civil, es va exiliar a Mèxic.

19. Eduardo de Ontañón (1929), «Final de Arlanza», El Sol (10 de novembre).

20. Es poden consultar els comentaris sobre l'extracció i la venda de les pintures a la premsa, per exemple, a La Vanguardia del dia 26 d'octubre de 1929 <http://hemeroteca.lavanguardia. com/preview/1929/10/26/pagina-26/33232119/pdf.html>.

21. Marceliano Santa María Sedano (1866-1952). Va néixer a Burgos. Va ser pintor i acadèmic de la Real Academia de Bellas Artes de San Fernando. Es pot consultar la seva intervenció a «Informe proponiendo al gobierno de S. M. la adquisición por el Estado de unas pinturas murales existentes en una finca que posee en San Pedro de Arlanza, jurisdicción de Hortigüela, provincia de Burgos, Doña Carlota Barbadillo y Loigorri», Boletín de la Real Academia de Bellas Artes de San Fernando, Madrid, 14 de novembre de 1924. II època. núm. 72.

22. Francisco Javier Sánchez Cantón (1891-1971), historiador de l'art $i$ acadèmic de la Real Academia de Bellas Artes de San Fernando. L'any 1922 va ser nomenat subdirector del Museu del Prado i en va ser director el 1960.

23. Teodoro de Anasagasti y Algán (1888-1938), reconegut arquitecte i membre de la Real Academia de Bellas Artes de San Fernando.

24. Josep Colominas i Roca (Barcelona, 1884-1959), arqueòleg i deixeble de Norbert Font Sagués i de Pere Bosch Gimpera. Va publicar nombrosos estudis sobre arqueologia de Mallorca, Eivissa, Montserrat i l'Urgell, entre d'altres.

25. Josep Gudiol i Ricart (Vic, 1904 - Barcelona, 1985), arquitecte i historiador de l'art. Va ser nebot de Josep Gudiol i Cunill, reconegut director del Museu Episcopal de Vic. A partir de 1930 va visitar diverses vegades els Estats Units d'Amèrica, on va contactar amb importants medievalistes i hispanistes, com ara Arthur Kingsley Porter, Chandler Rathfon Post o Walter William Spencer Cook. Durant la Guerra Civil espanyola (1936-1939) va participar en el salvament $i$ la recuperació del patrimoni artístic i posteriorment es va exiliar a França i als Estats Units. L'any 1941 va fundar l'Institut Amatller d'Art Hispànic a Barcelona, seguint el model de la Frick Art Reference Library, de Nova York. Així mateix, va crear una important col-lecció bibliogràfica sobre art hispànic, denominada «Ars Hispaniae». També va realitzar obres de síntesi sobre la pintura romànica $\mathrm{i}$ gòtica, dels mestres del Segle d'Or espanyol i també sobre Francisco de Goya. Sobre Josep Gudiol i Ricart es poden consultar, entre altres autors: Miquel dels Sants Gros i Pujol (1985), «Josep Maria Gudiol i Ricart in memoriam», Ausa, 114-115, Vic (novembre), p. 449-456; Francesc Fontbona, (1985), «Josep Maria Gudiol i Ricart, tractadista d'art», Ausa, 114-115, Vic (novembre), p. 459-460; Josep. Gudiol (1987), 
Tres escritos de Josep Maria Gudiol $i$ Ricart, Barcelona, Arturo Ramón i Manuel Barbié; Eulàlia Gudiol Corominas (1997), Josep Gudiol Ricart, Vic, Patronat d'Estudis Osonencs; Francesc FonTBONA (1998), «La Exposición Internacional del College Art Association, en Nueva York, 1933», a Goya, Madrid (gener-febrer), núm. 262, p. 13; Immaculada Socias BATET (2013), «Contribució al coneixement de l'etapa americana de Josep Gudiol Ricart i la seva relació amb Walter William Spencer Cook», a Ignasi Domènech i Bonaventura. BAssegoda (coord.), Antiquaris, experts, col-leccionistes i museus: El comerç, l'estudi i la salvaguarda de l'art a la Catalunya del segle $X X$, Barcelona, Universitat Autònoma de Barcelona, i Guillem CañameRAS (2013), La trajectòria de Josep Gudiol Ricart entre 1930 i 1940: Contribucions $i$ aportacions al seu estudi, treball de màster, Universitat de Barcelona, Departament d'Història de l'Art.

26. Josep Colominas Roca i Josep Gudiol Ricart (1923), Sepulcres megalítics de l'Ausetània, Barcelona, Impremta de la Casa de la Caritat.

27. Arxius dels museus d'art de Harvard. Correspondència entre Walter Cook i Paul J. Sachs, 9 d'octubre de 1930. Vegeu Eulàlia Gudiol Corominas, Josep Gudiol Ricart, op. cit., p. 31

28. Sobre aquests aspectes, es pot consultar Eulàlia Gudiol CoROMINAS, op. cit. p. 31; Francisco Gracia Alonso (2011), Pere Bosch Gimpera: Universidad, politica, exilio. Madrid, Marcial Pons, p. 138.

\section{El carrer de la Corríbia de} Barcelona - desaparegut el 1953començava al carrer de la Tapineria i passava davant de les escales de la catedral fins a enllaçar amb la plaça Nova.

30. Eulàlia Gudiol i corominas, op. cit., p. 31 .

31. Ròmul Bosch i Catarineu (1894-1936) va ser un empresari català del sector tèxtil i un gran col-leccionista d'art.

32. Teresa Amatller i Cros (18731960) va crear, l'any 1941, la fundació privada Institut Amatller d'Art Hispànic. Josep Gudiol i Ricart en va ser el primer director.

33. Eulàlia Gudiol Corominas, op. cit., p. 34

34. Josep Gudiol i Cunill (Vic, 1872 - Vic, 1931) fou un sacerdot, arqueòleg i historiador de l'art català. També va ser director del Museu Episcopal de Vic des de l'any 1898 fins que va morir. Entre la gran quantitat d'obres que va escriure hi trobem Les nocions d'arqueologia sagrada catalana (1902) Els Trescentistes (1924).

35. Arxius del Metropolitan Museum of Art (d'ara endavant, MMAA), James Joseph Rorimer, informe confidencial, 1931, Office of the Secretary Records.

36. Les fotografies d'aquests diagrames, divulgats en diverses publicacions, es conserven, entre altres llocs, a la Frick Art Reference Library, de Nova York, el Metropolitan Museum of Art, l'Institut Amatller d'Art Hispànic

i el Museu Nacional d'Art de Catalunya.

37. Segons el testimoni de Julien Chappée, ja s'havien fet fotografies del conjunt dels murs d'Arlanza a finals del segle XIX o principis del xx (vegeu la nota 6). Les sèries fotogràfiques que s'han examinat són les de la Frick Art Reference Library, de Nova York. La majoria es van recopilar el 1933 i constitueixen un veritable tresor, perquè permeten veure els diferents estats dels frescs de San Pedro de Arlanza. No obstant això, cal advertir que el conjunt fotogràfic de la Frick és de procedències diferents. Així, hi ha tres fotografies aquarellades de Gudiol reproduïdes per la fotògrafa nord-americana Ira W. Martin (1886-1960), les quals van ser dipositades a la Frick per Walter W. S. Cook. Un altre fotògraf va ser Diego López de Haro, les proves del qual van passar al Photo Club de Burgos i van ser venudes posteriorment a la Frick. També hi consten fotografies realitzades per Arthur Byne i venudes per ell mateix. L'historiador de l'art Arthur Kingsley Porter va realitzar també nombroses fotografies, probablement captades durant la seva estada a Espanya l'any 1924, moltes de les quals també es conserven al Fogg Art Museum, de Harvard. Tanmateix, la quantitat més important de tota la sèrie, 23 fotografies, prové de l'Arxiu d'Arqueologia Catalana, el centre fundat per Gudiol i Ricart, les quals van ser realitzades $i$ venudes per ell mateix el 1933.

38. James Joseph Rorimer (19051966) va estudiar a la Harvard.University. El 1927 va iniciar la seva carrera professional al Metropoli$\tan$ Museum of Art com a assistent de Joseph Breck, conservador del Departament d'Arts Decoratives (1927-1929), i tots dos van treballar en la museografia dels Cloisters. Després de ser inaugurats el 1938, Rorimer va ser nomenat conservador del nou museu i, uns quants anys més tard, director. Amb l'ajuda financera de John D. Rockefeller va comprar importants peces, com ara els famosos tapissos de l'Unicorn o el sepulcre d'Ermengol VII, comte d'Urgell. El 1943 Rorimer es va enrolar a l'exèrcit nordamericà, a la secció denominada Monuments Men, que va treballar per la salvaguarda de l'art i el retorn de les peces d'art robades pels nazis. Aquest grup, constituït per homes i dones de tretze països, la majoria dels quals tenia experiència en el món dels museus, arxius o altres institucions culturals, es van oferir com a voluntaris durant la II Guerra Mundial (1939-1945). Quan la guerra es va acabar, Rorimer es va incorporar al museu com a director dels Cloisters. Fou director del Metropolitan Museum of Art des de 1955 fins a 1966, any en què va morir.

39. MMAA, James J. Rorimer, informe confidencial, Office of the Secretary Records, 1931.

40. MMAA, carta de Josep Gudiol a James Rorimer, 18 de maig de 1936, Office of the Secretary Records.

Traducció de l'autora: «Els frescs cobrien les parets de la segona planta dins d'una torre. Recordo que li vaig proporcionar a vostè alguns dibuixos que mostraven la composició exacta del conjunt. L'entrada a aquesta sala decorada amb pintures es realitzava a través d'un portal molt petit $\mathrm{B}$, el qual comunicava aquest espai amb la sagristia de l'església i per una gran escala que arrencava des de la planta baixa, on hi havia una porta $\mathrm{C}$ que donava a un claustre petit del monestir. La decoració d'aquesta sala, colllocada dins de la torre de pedra, va ser modificada al segle XVII o xviII i ha estat molt difícil reconstruir-ne exactament la forma original. Estic segur que la porta d'accés era moderna. Lamento ara ser de poca ajuda. Vaig ser bastant estúpid de no fer amb cura l'alçat d'aquest important edifici [...]».

41. Kathryn BRUSH (2003), Vastly More than Brick and Mortar: Reinventing the Fogg Art Museum in the 1920s, Harvard-Tale; Kathryn. BRUSH (1999), «German Kunstwissenschaft and Practice of Art History in America after World War I: Interrelationships, Exchanges, Contexts", a Marburger Jabrbuch für Kunstwissenschaft, i Susan BALl (ed.) (2011), The Eye, the 
Hand, the Mind, Nova York, The College Art Association, Rutgers University Press, The State University of New Jersey.

42. John Pierpont Morgan (18371913) va ser un industrial $i$ un financer americà. Va aplegar una meravellosa colllecció d'art medieval i també de manuscrits, una gran part de la qual la va llegar al Metropolitan Museum of Art.

43. George Gray Barnard (18631938) va néixer a Bellefonte, Pennsilvània. Va estudiar escultura a l'Art Institute de Chicago. El 1883, quan tenia vint anys, va ingressar a l'École Nationale Supérieure des Beaux-Arts de París. A França va iniciar la seva col-lecció de fragments arquitectònics i escultòrics romànics i gòtics. El 1906 va començar a comprar restes de SaintGuilhem-le-Désert, mentre que el 1913 va adquirir algunes peces de Cuixà a un antiquari de París. Després va visitar Prada de Conflent, on va aconseguir elements arquitectònics que van permetre la reconstrucció de part del claustre de Cuixà als Cloisters de Nova York. En el seu moment, Barnard no va poder comprar la resta dels capitells i columnes del claustre perquè estaven reutilitzats als banys de Prada, els quals l'any 1955 es van desmuntar per reconstruir la meitat del claustre de Cuixà.

44. Isabella Stewart Gardner (1840-1924) va ser membre d'una rica família d'origen irlandès. Al llarg dels seus viatges per Europa es va aficionar al món de les antiguitats i l'art medieval, però el seu èxit com a col-leccionista de pintura va ser degut en gran part a l'historiador d'art Bernard Berenson, que a principis del segle $\mathrm{xx}$ va posar de moda el Renaixement entre els col-leccionistes americans.

45. James Joseph Rorimer (1972), Medieval Monuments at the Cloisters as they were and as they are: Revised Edition by Katherine Serrell Rorimer, Nova York, Metropolitan Museum of Art (1941).

Traducció: de l'autora «La seva imaginació inicial, així com la seva dedicació, van aconseguir l'èxit de l'escultor George Grey Barnard, un dels col-leccionistes més romàntics $\mathrm{i}$ forts de l'actualitat. Va ser la primera persona a reconèixer la importància d'un museu d'art medieval i li devem gratitud i admiració, perquè va reunir les diverses seccions dels claustres, els quals van fer possible la reconstrucció dels quatre claustres que són el nucli de la nostra col-lecció».
46. Sobre el museu dels Cloisters hi ha una bibliografia abundant, entre la qual es pot consultar: James J. Rorimer i Margaret B. FreEmaN (1938), The Cloisters: The Building and the Collection of Medieval Art in Fort Tryon Park, New York, Nova York, Metropolitan Museum of Art; James, J. Rorimer (1938), «New acquisitions for the Cloisters", a The Metropolitan Museum of Art Bulletin (maig), 33(5), part 2; Ella S. Siple (1938), «Medieval Art at the New Cloisters», The Burlington Magazine for Connoisseurs (agost), 73(425), p. 83; James J. Rorimer (1941), Medieval Monuments at the Cloisters as they were and as they are: Revised Edition by Katherine Serrell Rorimer, Nova York, Metropolitan Museum of Art, 1972; Calvin Tomkins (1970), «The Cloisters... The Cloisters... The Cloisters...", The Metropolitan Museum of Art Bulletin, 28(7) (8 de març); Peter Barnet (2012), The Cloisters Medieval Art and Architecture, 75è aniversari, Nova York, Metropolitan Museum of Art; Timothy B. Husband (2013), "Creating the Cloisters", The Metropolitan Museum of Art Bulletin, LXX(4); José Miguel Merino DE CÁCEREs (2013), «El coleccionismo americano y la expatriación del románico hispano: Portadas, claustros y ábsides», a La diáspora del románico hispano: De la protección al expolio, Aguilar de Campoo, Fundación Santa María la Real, p. $94-132$.

47. James J. Rorimer (1938), "New acquisitions for the Cloisters", The Metropolitan Museum of Art Bulletin, 33(5), part 2 (maig), i Alfred M. FrankFURTER (1938), «The opening of the Cloisters», Art News, 36(7) (maig).

48. Eulàlia Gudiol Corominas, op. cit., p. 37.

49. Eulàlia Gudiol Corominas, op. cit., p. 38.

50. Arxius dels museus d'art de Harvard. Correspondència entre Walter Cook i Paul J. Sachs, 9 d'octubre de 1930.

\section{James J. Rorimer també hi va} intervenir el 1956 intercanviant diversos fragments pictòrics de San Baudelio de Berlanga per l'absis de San Martín de Fuentidueña a la mostra dels Cloisters de Nova York. Vegeu Maria José MarTínez RuIz (2013), «La venta y expolio del patrimonio románico de Castilla y León: El caso de las pinturas murales», a Pedro Luis HuerTa (coord.), La diáspora del románico hispano: De la protección al expo- lio, Aguilar del Campoo, Fundacion de Santa Maria la Real, p. 35.

52. MMAA, James J. Rorimer, informe confidencial, 1931, Office of the Secretary Records.

Traducció de l'autora: «[...] va ser possible pel Sr. Colominas (un antiquari de Barcelona), i altres, comprar els frescs que ara son a Amèrica».

53. MMAA, James J. Rorimer, informe confidencial, 1931, Office of the Secretary Records, i Luis A. Grau Lobo (1996), La Pintur románica en Castilla y León, Valladolid, Junta de Castilla y León, Consejería de Educación y Cultura, p. 169.

54. María José Martínez Ruiz (2013), «La venta y expolio del patrimonio románico de Castilla y León: El caso de las pinturas murales», a Pedro Luis Huerta (coord.), La diáspora del románico hispano: De la protección al expolio, Aguilar del Campoo, Fundacion de Santa Maria la Real, p. 55.

55. MMAA, compromís de venda de Josep Gudiol i Ricart, 16 de febrer de 1931, Office of the Secretary Records.

Traducció de l'autora : «Jo, J. Gudiol, en qualitat d'agent i propietari parcial dels frescs d'Arlanza del segle XIII, dono, fins a finals de febrer, la primera opció al Metropolitan Museum of Art per comprar els frescs».

56. MMAA, document de conformitat entre Edward Robinson, director del Metropolitan $\mathrm{Mu}$ seum of Art, i Josep Gudiol, 10 d'octubre de 1930, Office of the Secretary Records. Traducció de l'autora «Es va arribar a aquest acord entre el difunt Sr. Robinson i jo després del meu viatge a Espanya, on vaig veure per primer cop els frescs a casa de Gudiol. Aquests ja havien estat arrencats d'Arlanza quan jo hi vaig ser el 1929».

57. MMAA, Purchases Breck, 1929-1930, 1 d'octubre de 1930, Office of the Secretary Records.

58. MMAA, document de conformitat entre Edward Robinson, director del Metropolitan $\mathrm{Mu}$ seum of Art, i Josep Gudiol, 10 d'octubre de 1930, Office of the Secretary Records. Rorimer explica aquesta qüestió en una nota afegida al document.

59. MMAA, informe confidencial, James J. Rorimer, s. d., Office of the Secretary Records. 
Traducció: «El 1928, J. Gudiol, jove arquitecte, nebot del Dr. Gudiol, destacat arqueòleg i director del Museu de Vic, va retirar els frescs d'Arlanza i els va traslladar [...]».

60. MMAA, informe confidencial, James J. Rorimer, s. d., Office of the Secretary Records.

Traducció de l'autora: «El professor Chandler Rathfon Post, de la Universitat de Harvard, en el seu llibre més recent $i$ autoritzat sobre pintura espanyola, diu que la part superior de la sala estava adornada amb les restes de grans animals magníficament concebuts, així com amb monstres fets d'una forma extraordinària, influïts per la grotesca imaginació habitual a l'època del romànic de realitzar aquests productes de la fantasia». Rorimer acabava el seu informe assenyalant que «els frescs havien estat publicats per importants estudiosos de l'art espanyol (consulteu la bibliografia). Hi ha una divergència d'opinions sobre si els frescs són de finals del segle XII o de principis del segle xIII. Tanmateix, sembla que és raonable pensar que foren pintats al voltant de 1220 . Els animals i els monstres formen un cicle únic de la pintura del fresc espanyol. Quant a la bellesa i l'audàcia del disseny, així com pel que respecta a la riquesa del color, cal considerar que aquests frescs són immillorables.

61. MMAA, carta de James J. Rorimer a Josep Breck, 6 de gener de 1931, Office of the Secretary Records.

62. Joseph Breck (1885-1933) va ser assistent del Departament d'Arts Decoratives (1909-1914), conservador del Departament d'Arts Decoratives (1917-1933), assistent del director del Metropolitan Museum of Art (1917-1933) i director dels Cloisters (1932-1933).

63. MMAA, carta de Joseph Breck a John D. Rockfeller, 27 de gener de 1931, Office of the Secretary Records.

64. MMAA, carta de John D. Rockefeller a Joseph Breck, 17 de febrer de 1931, Office of the Secretary Records.

65. George Blumenthal (18581941) va néixer a Frankfurt en el si d'una família jueva. Va ser un important financer que durant molts anys va formar part del consell del Metropolitan Museum of Art, el qual va presidir de 1934 a 1941. Una de les seves adquisicions més notables va ser el claustre de Vélez-Blanco, comprat a París el
1913, que el 1964 va ser reconstruït al Metropolitan Museum of Art.

66. MMAA, carta de Joseph Breck a Josep Gudiol, 10 de febrer de 1931, Office of the Secretary Records.

67. MMAA, cablegrama de Josep Gudiol a Josep Colominas, 1931, Office of the Secretary Records.

68. MMAA, cablegrama de Josep Colominas a Josep Gudiol, 13 de febrer de 1931, Office of the Secretary Records.

69. MMAA, cablegrama de Josep Colominas a Josep Gudiol, 14 de febrer de 1931, Office of the Secretary Records.

70. MMAA, document de compra de les pintures d'Arlanza, Josep Gudiol i Ricart, 16 de febrer de 1931, Office of the Secretary Records.

Traducció de l'autora: «Jo, J. Gudiol, com a agent i en part propietari dels frescos del segle XIII d'Arlanza, amplio fins a finals de febrer la primera opció de compra al Metropolitan Museum of Art per adquirir els frescos sota les condicions següents: vendrem els dos grans panells, l'un amb un lleó i l'altre amb un drac alat o serpent, i els frisos inferiors per 30.000 dòlars. El preu de tot el grup de frescos d'Arlanza, cinc de grans i deu petits panells, és de 40.000 dòlars. Faré la transferència dels frescos, però no els treballs de restauració, excepte en la mesura que sigui necessària per a la preservació final. Encara que el Museu només compri els dos panells, es compromet a guardar la resta dels frescos fins que finalitzi el meu treball de transferència».

71. MMAA, carta de Joseph Breck a John D. Rockfeller, 17 de febrer de 1931, Office of the Secretary Records.

72. MMAA, factura de pagament del Metropolitan Museum of Art a Josep Gudiol, 24 de febrer de 1931 Office of the Secretary Records.

73. MMAA, document de venda firmat per Josep Gudiol, 24 de febrer de 1931, Office of the Secretary Records.

74. MMAA, correspondència entre Josep Breck i Josep Gudiol i Ricart, 25 de febrer de 1931, Office of the Secretary Records.

75. MMAA, comunicació de Josep Breck a Robert W. de Forest sobre la compra dels dos frescs d'Arlanza, 24 de febrer de 1931.
76. MMAA, correspondència entre Josep Breck i John D. Rockefeller, 25 de febrer de 1931, Office of the Secretary Records.

77. MMAA, carta de James Rorimer a Chandler R. Post, 16 d'abril de 1931, Office of the Secretary Records.

Traducció de l'autora: «He estat pensant en el problema dels frescs d'Arlanza. Li vull demanar, com un favor personal per a mi i també per al Metropolitan Museum of Art, que no parli a Espanya, ni enlloc més, sobre aquests frescs. Realment és un assumpte molt seriós, i no volem que se sàpiga que els tenim. Josep Gudiol, sobre qui vostè va parlar, no era el propietari dels frescs, sinó que estava treballant per transferir-los, així com també per fer el tracte amb els propietaris».

78. MMAA, carta de James Rorimer a Josep Gudiol, 16 d'abril del 1931, Office of the Secretary Records.

79. MMAA, carta de James J. Rorimer a Joseph Breck, 26 d'octubre de 1931, Office of the Secretary Records. Traducció de l'autora: «Si aquesta nit tinc notícies de Gudiol veuré si té ganes de vendre els frescs o qualsevol altre material d'importància».

80. MMAA, carta de Joseph Breck a George Blumenthal, 11 de novembre de 1931, Office of the Secretary Records.

81. Immaculada Socias BATEt (2013), «L'etapa americana de Josep Gudiol Ricart i la seva relació amb Walter William Specer Cook», a Bonaventura BASSEgODA i Ignasi Domènech (ed.), Antiquaris, experts, col-leccionistes i museus: $E l$ comerç, l'estudi i la salvaguarda de l'art a la Catalunya del segle XX. Barcelona, Universitat Autònoma de Barcelona.

82. MMAA, carta de James J. Rorimer a Josep Gudiol i Ricart, març de 1934, Office of the Secretary Records.

83. Dimitra Gkozkgou-GianNopoulou, La Sociedad Española de los Amigos del Arte, 1909-1936, tesi doctoral presentada el 30 de setembre de 2019, II, p. 1213.

84. Yolanda Pérez Carrasco (2018), Patrimonio confiscado: La incautación y éxodo de colecciones de arte privadas en Barcelona durante la Guerra Civil (1936-1939), Barcelona, Base. 
85. María José Martínez Ruiz, «La venta y expolio del patrimonio románico de Castilla y León:

El caso de las pinturas murales», a Pedro Luis HuerTa (coord.), La diáspora del románico hispano: De la protección al expolio, Aguilar del Campoo, Fundacion de Santa Maria la Real, p. 55.

86. Joan Ainaud de Lasarte (1993), «Les col·leccions de pintu- ra romànica del Museu Nacional d'Art de Catalunya», Butlleti dels Musen Nacional d'Art de Catalunya, p. 64 is.

87. MNAC. Junta de Museus. Reunió del dia 26 d'abril de 1973.

88. Aquest fragment va ser reproduït a Walter W. S. Cook i José GuDIOL (1950), Pintura e imaginería románicas, Ars Hispaniae: Historia
Universal del Arte Hispánico, 2a ed., Madrid, Plus Ultra, VI, p. 115.

89. Antonio Gallardo Ballart va néixer el 12 de març de 1936 . Va ocupar diversos càrrecs directius a l'empresa farmacèutica Almirall. Després de la mort del seu pare el 1988, ell i el seu germà Jordi van prendre les regnes del negoci i van potenciar la modernització i la internacionalització de l'empresa. 